Review Article

\title{
A Review of the Evaluation, Control, and Application Technologies for Drill String Vibrations and Shocks in Oil and Gas Well
}

\author{
Guangjian Dong ${ }^{1,2}$ and Ping Chen ${ }^{1,2}$ \\ ${ }^{1}$ State Key Laboratory of Oil and Gas Reservoir Geology and Exploitation, Southwest Petroleum University, \\ Chengdu, Sichuan 610500, China \\ ${ }^{2}$ College of Oil and Gas Engineering, Southwest Petroleum University, Chengdu 610500, China
}

Correspondence should be addressed to Guangjian Dong; rocdgj@hotmail.com and Ping Chen; chenping@swpu.edu.cn

Received 15 May 2016; Revised 16 August 2016; Accepted 29 August 2016

Academic Editor: Tai Thai

Copyright (C) 2016 G. Dong and P. Chen. This is an open access article distributed under the Creative Commons Attribution License, which permits unrestricted use, distribution, and reproduction in any medium, provided the original work is properly cited.

Drill string vibrations and shocks (V\&S) can limit the optimization of drilling performance, which is a key problem for trajectory optimizing, wellbore design, increasing drill tools life, rate of penetration, and intelligent drilling. The directional wells and other special trajectory drilling technologies are often used in deep water, deep well, hard rock, and brittle shale formations. In drilling these complex wells, the cost caused by V\&S increases. According to past theories, indoor experiments, and field studies, the relations among ten kinds of V\&S, which contain basic forms, response frequency, and amplitude, are summarized and discussed. Two evaluation methods are compared systematically, such as theoretical and measurement methods. Typical vibration measurement tools are investigated and discussed. The control technologies for drill string V\&S are divided into passive control, active control, and semiactive control. Key methods for and critical equipment of three control types are compared. Based on the past development, a controlling program of drill string V\&S is devised. Application technologies of the drill string V\&S are discussed, such as improving the rate of penetration, controlling borehole trajectory, finding source of seismic while drilling, and reducing the friction of drill string. Related discussions and recommendations for evaluating, controlling, and applying the drill string V\&S are made.

\section{Introduction}

With increasing demand for oil and gas, conventional oil and gas production is declining. The trend of the global oil and gas exploration is from conventional to unconventional oil and gas resources [1], from deep well to ultra-deep well, from the deep water to ultra-deep water [2-4]. In order to achieve industrial production capacity of unconventional oil and gas, directional well, horizontal well, and rotary steering system (RSS) must be used in the drilling process [5]. Vibrations are unavoidable since drilling is the destructive process of cutting rock either by chipping or by crushing. Different drill string vibrations and shocks (V\&S) occur in complex drilling environments [6-16], especially the poor drillability formation with extreme drill bit $V \& S$, deep well and ultra-deep well with the long drill string, the deep water to ultra-deep water with vortex-induced vibration (VIV) of slender marine structures, coal and shale formation with borehole instability, irregular borehole diameter, and well trajectory increasing the level of drill string V\&S. Drill string V\&S cause serious failures of drilling tools and while-drilling-monitoring equipment such as drill pipe, drill collar $[17,18]$, logging while drilling (LWD), measuring while drilling (MWD) [19], pressure and temperature while drilling (PTWD), engineering parameters while drilling (EPWD), pressure while drilling (PWD) [2022], and drill bits [23]. Typical drilling tools failure due to the different drill string V\&S are presented in Figure 1. According to statistics [18-23], nonproductive time (NPT) caused by the drill string V\&S account for $25 \%$ of total NPT every year, which seriously restrict the development of automatic drilling and the rate of penetration (ROP) as shown in Figure 2. On the other hand, the application of drill string V\&S can 


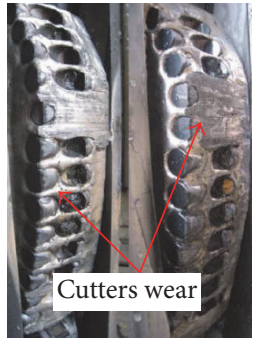

(a) Reamer failure

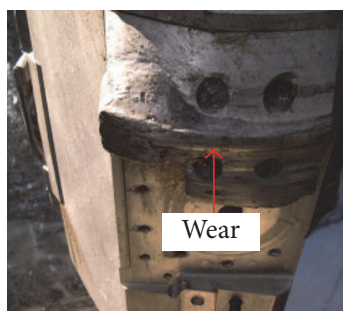

(d) Downhole measurement tool failure

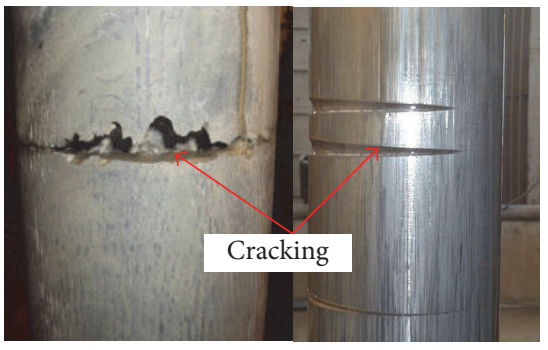

(b) Drill collars failure

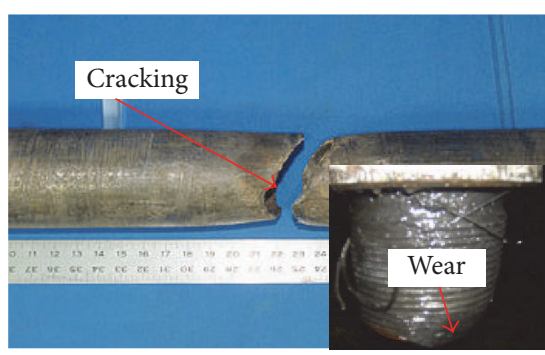

(c) Drill pipe failure

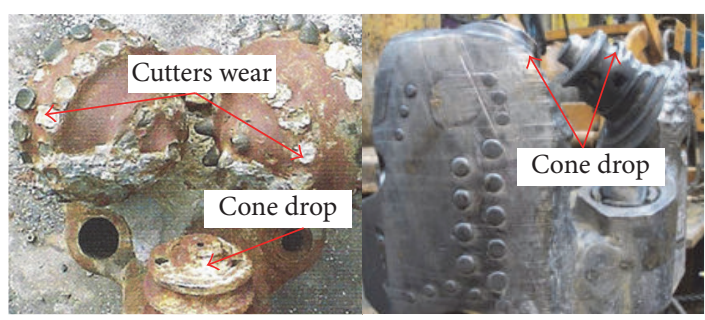

(e) Tricone bit failure

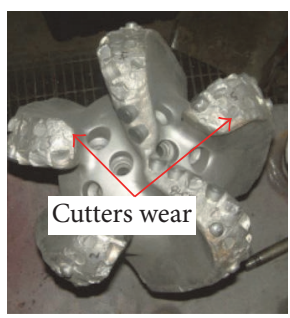

(f) PDC bit failure

FIgURE 1: Typical drilling tools failure due to the different drill string V\&S.

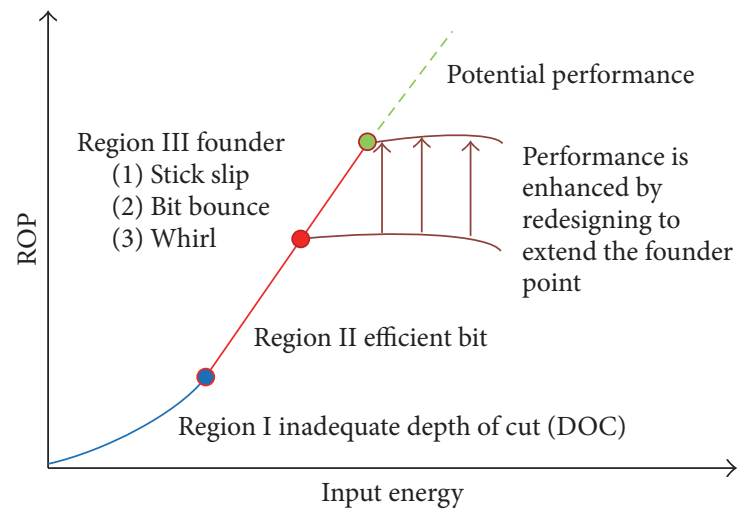

FIGURE 2: The relationship of drilling parameters, ROP, and input energy.

bring immeasurable economic benefits for the oil industry. Consequently, the research and investigation of drill string V\&S are an important and interesting problem.

Over the past 70 years [6], an increasing number of researchers have put effort in the investigation of the drill string V\&S to understand its root causes, modelling, evaluation, control, and applications. Several review articles about the theories and experiences of drill string V\&S have been published. The causes of severe drill string vibrations and guidelines of passive control were explained by Dareing [24]. The paper only focused on the bottomhole assembly (BHA) natural frequency to control drill string vibration. An overview on vortex-induced vibration (VIV) of slender marine structures was provided by Pan et al. [25]. The research and progress of concerning deep water riser VIV were overviewed and discussed, including evaluation of VIV analysis tools, experiments, appropriate fatigue calculation criteria, and coupling effects induced by axial and inline VIV. The computational fluid dynamics (CFD) need to be given more attention in the future work [25]. The comparative review of drill string torsional vibrations was focused by Patil and Teodoriu [26]. In this paper, the modelling and controlling torsional vibrations and experimentation using laboratory setups were reviewed. Based on the complexity of drilling phenomenon, using of the laboratory experiments to study the drill string torsional vibrations has been the best method. Another survey of approaches for stick-slip vibration suppression has been presented by Zhu et al. [27]. The passive vibration control and active vibration control were reviewed. A broad survey of drill string vibration modeling literature was presented by Ghasemloonia et al. [28]. In this survey, the models for torsional, axial, and lateral vibrations (uncoupled and coupled), boundary condition assumptions, and application to vibration mitigation were reviewed. Another broad study of seismic while drilling (SWD) technology has been presented by Poletto and Miranda [29, 30]. The general theory, data acquisition, date preprocessing, data processing, and applications of SWD were overviewed which can provide essential guideline for the researchers. However, there are very few overview article about the comprehensive evaluation, control, and application technologies for the drill string V\&S.

From the above analysis, a broad overview of evaluation technologies, control methods, and applications of almost all drill string V\&S types in the field of oil and gas wells can help the engineers and researchers to develop more advanced technologies which can be applied to control and take advantage of the drill string V\&S. The structure of the paper is as follows. The first part mainly compares the forms and evaluation technologies of drill string V\&S; the second 


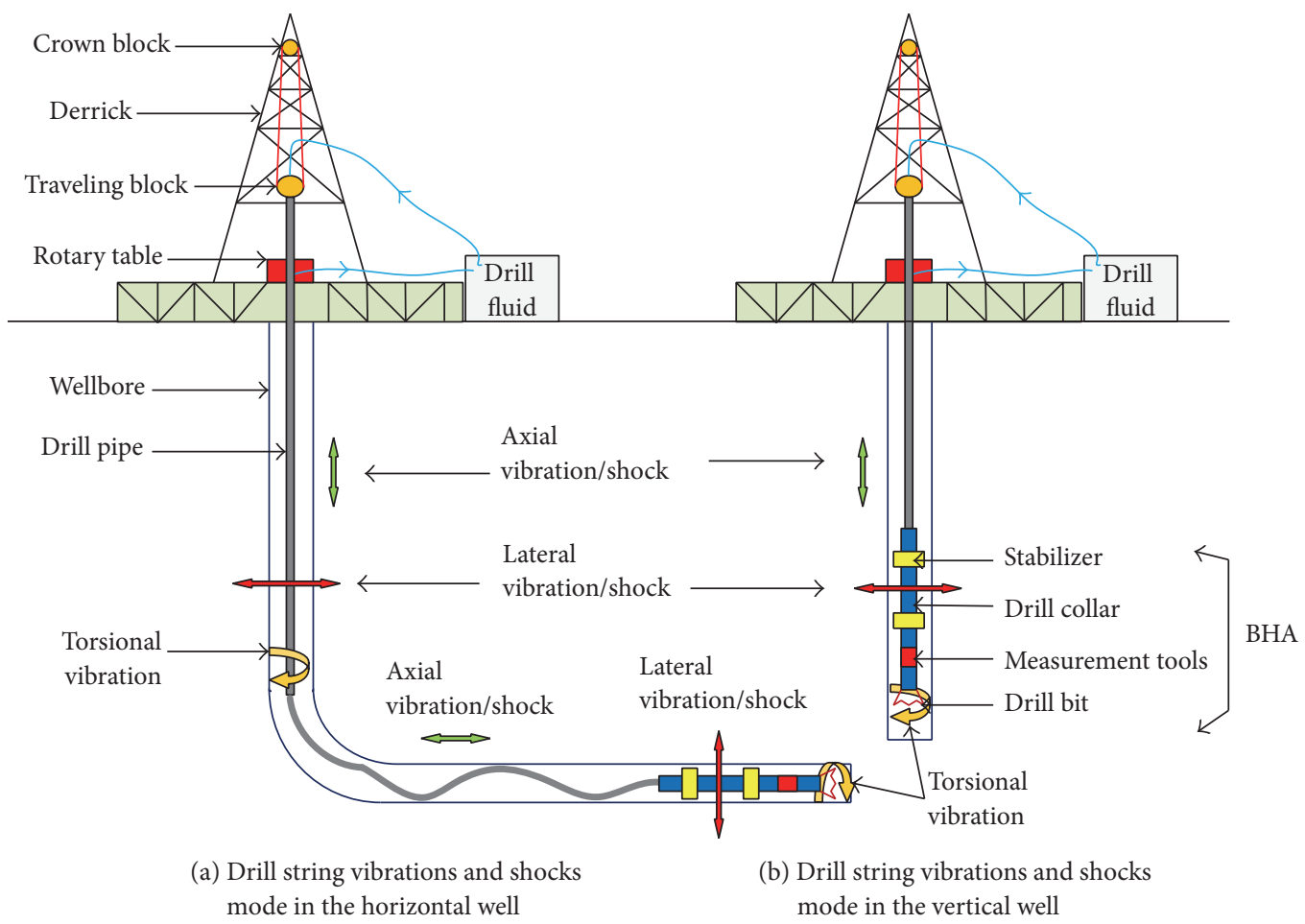

FIGURE 3: Typical drilling system and basic drill string V\&S forms.

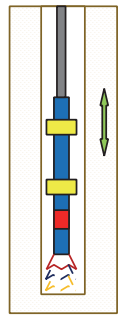

Bit bounce

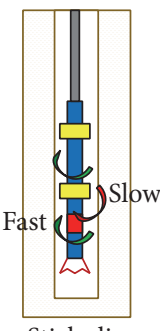

Stick slip

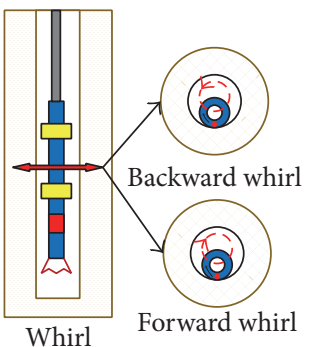

FIGURE 4: Severe drill string V\&S forms.

part pays attention to the passive control, active control, and semiactive control of string V\&S. The third part summarized the applications of drill string V\&S. The key problem of applications of drill string V\&S is discussed.

\section{Vibrations Forms and Evaluation Methods}

The investigation of drill string V\&S can be traced back to the 1960s $[69,70]$; the researchers focused on the dynamic behaviors of drill string bottom hole assembly (BHA). In the 1990s [71, 72], experts began to study the V\&S characteristics of whole drill string system. These results pay attention to the impact of bit-formation interaction on the drill string V\&S [39]. Based on systematic research results, related discussions and recommendations of key problems are proposed and discussed such as basic concepts, the classification and comparison of drill string V\&S forms, and the development and important indicators of vibration measuring instrument.
2.1. Vibrations and Shocks Forms. As a whole drilling system, slenderness ratio of the drill string is large, and the stiffness is very small, which is prone to deformation as shown in Figure 3. Drill string V\&S is divided into three basic forms such as axial (longitudinal) mode, torsional (rotational) mode, transverse (lateral) mode [24-28]. When the drill string moves along its axis of rotation, this is called axial vibration/shock. Torsional vibrations are caused due to an irregular rotation of the drill string when rotated from the surface at constant speed. When the drill string moves laterally to its axis of rotation it is called lateral V\&S. Due to many factors, very complex drill string V\&S are produced during actual drilling. According to past theories, indoor experiments, and field studies, the relationship of ten kinds of V\&S is listed, which contains basic forms, modes, frequencies, amplitudes response, and tool damage as shown in Table 1.

Based on the research in Table 1, some important results and concepts were summarized and illustrated. Maximum frequency and amplitude of drill string V\&S are $350 \mathrm{~Hz}$ and $200 \mathrm{~g}$, respectively. Stick-slip [17, 27], whirl [10, 18, 33, 34], VIV [25], lateral shock [39, 40], bit-chatter, and bit bounce $[31,32,73]$ are the key research objects as shown in Figure 4 . The stick-slip causing the drill string to periodically be torqued up and then spin free is a phenomenon of nonuniform drill string rotation. The whirl is the eccentric rotation of the BHA \& bits and is associated with the BHA rolling around the wellbore. Drill string lateral shock not only causes harm to drill string itself but also can cause whirl and serious damage to the wellbore quality [74]. VIV can be produced by the riser-water interaction during deep water 


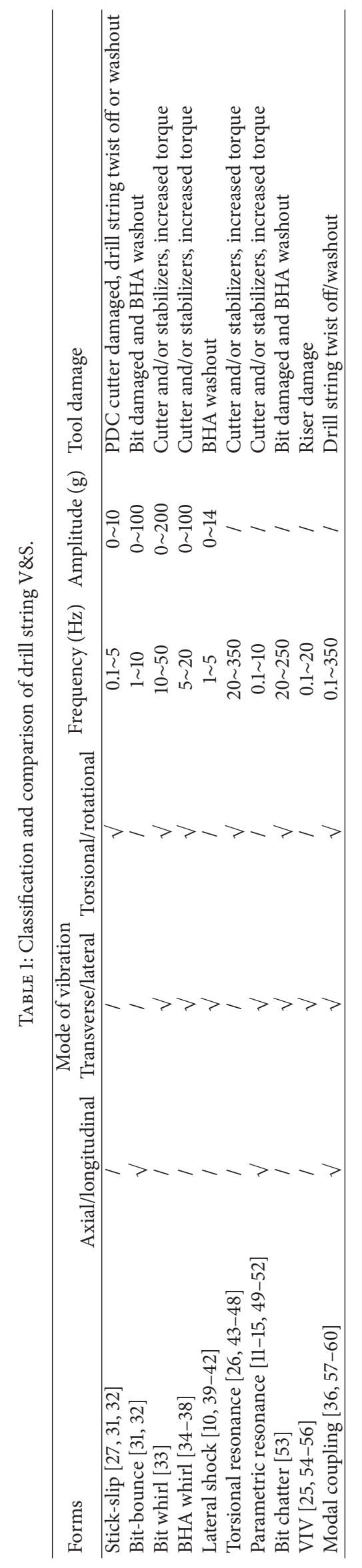


drilling process [25] and is a kind of special lateral vibration, which has a great damage to the deep water drilling riser. Bitchatter is the high-frequency resonance of BHA and bits. Bit bounce is the axis impact motion of drill string. The typical environment of drill string V\&S forms is also different and very complex. The drilling environment where longitudinal vibrations develop frequently is hard rock, vertical well, cone bits (one-cone bits, two-cone bits, and tricone bits), and hybrid bits $[19,24]$. The drilling environment where torsional vibrations develop easily is hard formations or salt, directional or deep wells, polycrystalline diamond compact (PDC) bits with high WOB, drag bits, and hybrid bits [17]. The drilling environment where transverse vibrations develop typically is softer or interbedded formations with different lithology, vertical, or horizontal wells $[17,19,40]$. The borehole instability occurs easily in the interbedded formations and causes the borehole size enlarging. The lateral drill string V\&S can be induced from either bit whirl or drill string flexes during bit bounce.

From above review, there is a very complex coupling relationship of the drill string V\&S. The relationship has not been clarified so far. Many years of research for drill string V\&S guide us to find new method to study the key problem. Simplistic research methods and models are difficult to solve the complex dynamic engineering problems of drill string. At present, rapidly developing computer technology has penetrated into all social sectors which can solve complex coupling issues. In order to clarify the rules of dynamic drill string, the researchers should fully utilize modern computing methods and try to establish a model close to the real drilling environment. According to field measured data correct theory model, the macro- and micromethods should be combined; complex V\&S problems of drill string may have a clear understanding. Macromethods mainly focus on the structures dynamics and multibody dynamics. The micromethods should pay more attention to the response mechanism of V\&S signals of bits breaking rock at the microand mesoscales, because the V\&S signals contain complex motion characteristics of drill string and bits.

2.2. Evaluation Technology. Before controlling the drill string $V \& S$, the relationship between vibration forms, vibration level, and downhole tools failure must be clarified, so the evaluation technologies to solve the problem of drill string dynamic failure need to be studied. Downhole drilling tools failure occurs in two typical modes [49]. On the one hand, when the vibration frequency is close to the natural frequency of drill string, the drill string resonance occurs, and the peak response value approximates or exceeds the limit strength of drilling tools breakage failure. On the other hand, the drilling tools show fatigue damage in an environment with long-term or repeated vibrations or impacts. Fatigue is the main reason for drill string failure [75]; more than $75 \%$ of the fracture failure belongs to fatigue fracture [76]. According to statistic data $[75,76]$, gas drilling accounts for $50 \%$ and fluid drilling accounts for $16 \%$ in all the drilling tools failure.

Evaluation technologies were established by long-term theoretical research and application of measurement technologies. There are two kinds of evaluation methods for drill string V\&S. One kind is to establish the failure model and predict the life of the drill string based on fracture mechanics and damage mechanics. The failure of drill string joints and load calculation methods under various working conditions was studied by Bailey and Smith [77]. It is remarked that material fatigue strength decreases with the increase of static stress, but the model did consider the dynamic stress. Permanent scratches on the drill pipe surface were analyzed by Hossain et al. [78]. It is noted that permanent scratches lead to stress concentration and fatigue damage of the drill pipe. A comparative design approach to reduce the drill string fatigue was established by Hill et al. [79]. This design method is to quantitatively express the relative fatigue performance based on the crack extension model. A fatigue life model was proposed by $\mathrm{Wu}[80]$. This model considers the calculating bending stress and fatigue of the dangerous drill string parts. The bending stress is directly related to the lateral drill string $\mathrm{V} \& \mathrm{C}$. The force and deformation of drill string using finite element method (FEM) were investigated by Millheim and Apostal [71]. 2D and 3D model of drill string V\&C were developed. According to different rotating speed, the drill string rotational energy levels can be divided into low energy stable, moderate energy unstable, high energy unstable, and high energy stable. This study is a typical achievement of drill string V\&C. A dynamic failure model of drill string was proposed by Chi et al. [43]. This model considers the effect of torsional vibration and axial vibration at the same time. A cumulative failure method of drill string $V \& C$ was suggested by Baryshnikov et al. [75]. This method based on full-scale drill string fatigue test results considers the fatigue damage and crack propagation. However, this method is difficult to calculate the drill string fatigue behavior under the downhole coupling V\&S conditions. A working life calculation method of drill string V\&C considering the temperature for MWD was developed by Wassell [81]. The method is used to establish vibration limitation and determine accumulative vibration damage. A drill string failure model using the fault tree analysis method was established by Zang et al. [82]. This model considers many factors such as corrosion load, material strength, manual operation, and tool quality, but it did not quantify the effect of vibration. The above is theoretical research about the evaluation of drill string V\&C. In the process of practical application, these models and methods provide important support for the failure prevention of drill string. However, because of the complexity of drill string V\&C, the predicted results had a large deviation from actual results on account of the above evaluation methods of drill string.

Therefore, the practical measuring method is another effective evaluation method of drill string. In order to obtain dynamic failure model range and experience model, the measured V\&S data and the observed failure are combined. Hence, the vibration measurement tools are the key technology and determine the accuracy and stability of evaluation approach. The development of dynamic parameter measurement technology can be divided into four stages as shown in Table 2. In the first stage [61], downhole measure and storage is an obvious characteristic, and the main purpose is to record bit data under different drilling conditions, which 

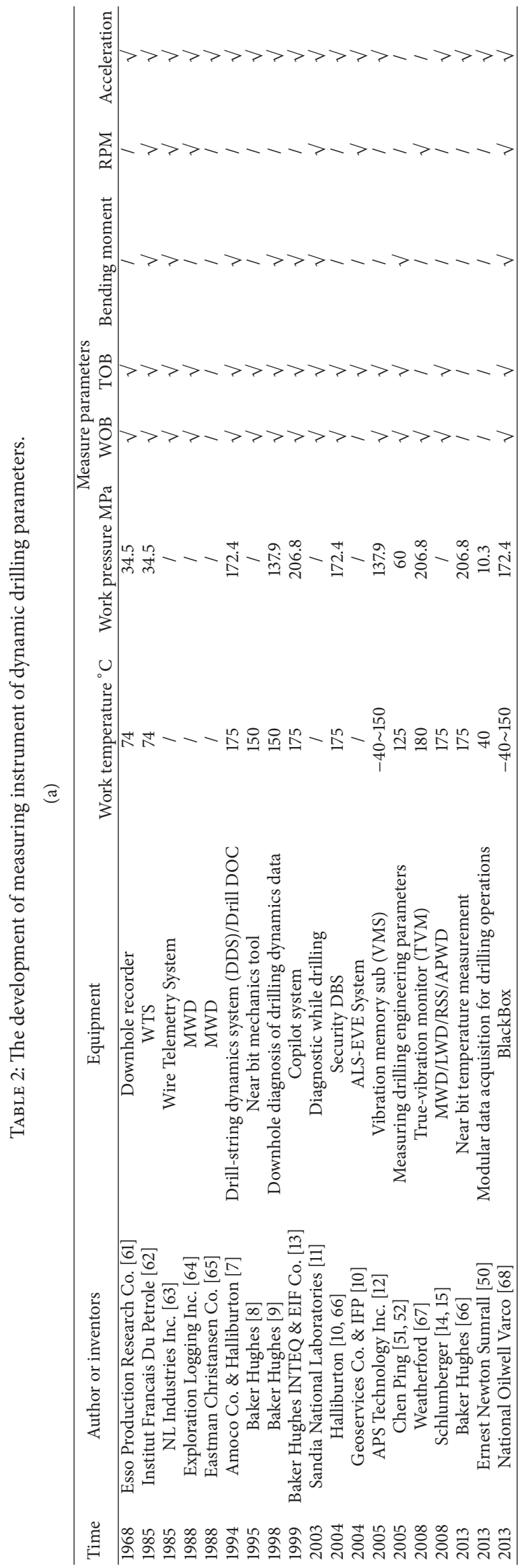

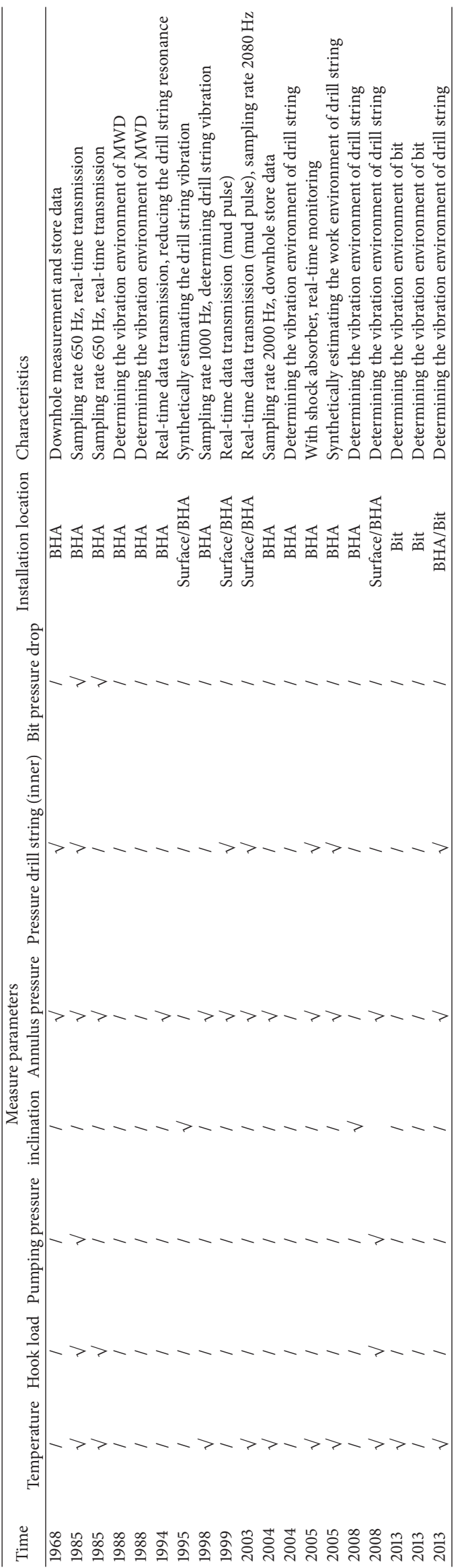




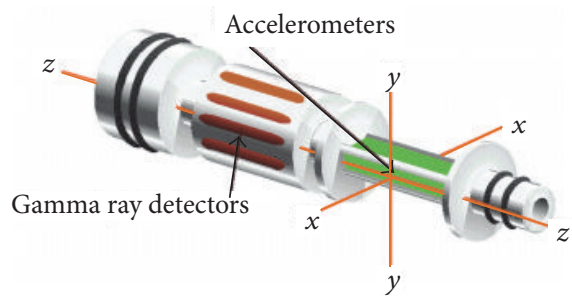

(a) DDS sensor consists of triaxial accelerometers (Halliburton)

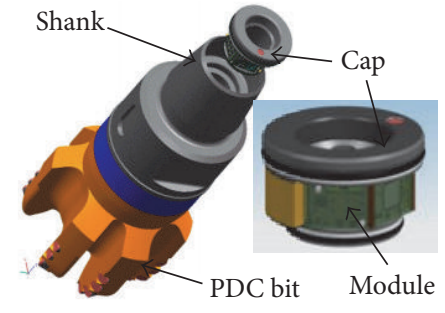

(b) In-bit dynamic sensor (Baker Hughes)

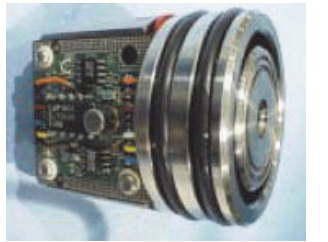

(c) Annular pressure while drilling measurements (Schlumberger)

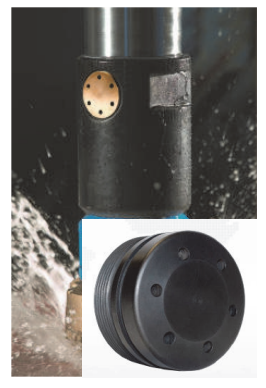

(d) BlackBox Eclipse downhole measurement tool (NOV)

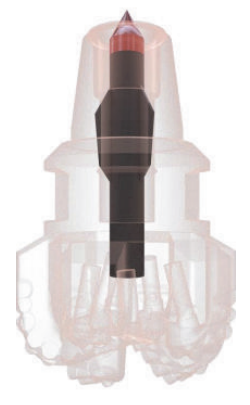

(e) BlackBox HD downhole dynamics recorder (NOV)

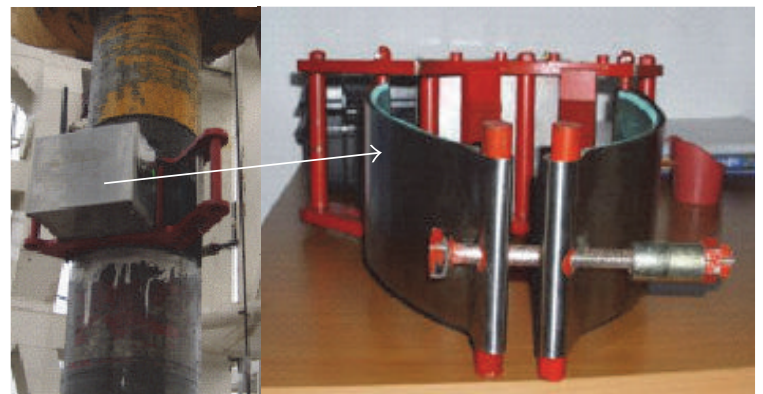

(f) Surface vibration measurement tool (CPU)

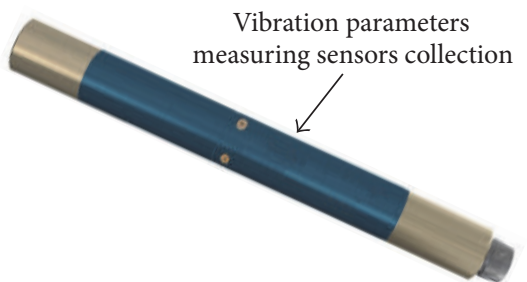

(g) BlackBox enhanced measurement system tool (NOV)

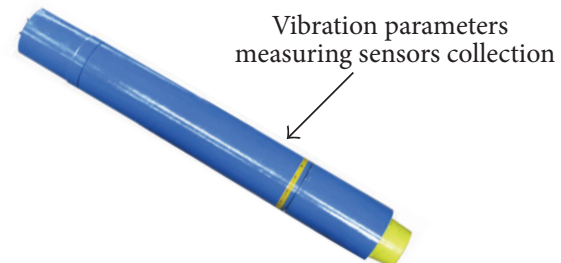

(h) Engineering parameters while drilling tool (SWPU)

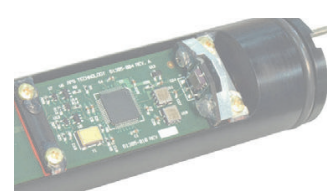

(i) Vibration memory module (APS)

FIgURE 5: Typical and latest vibration measurement tools.

is provided for bit design. In the second stage [61-63, 65], data real-time transmission became a reality. It can be divided into wired transmission and wireless transmission. Wired transmission (cable transmission) rate is high, but it cannot be applied to rotary drilling, and field operations are cumbersome. Wireless transmission (mud pulse transmission) rata is lower than wired transmission, but the operation of wireless transmission is easy. In the third stage [8-10], monitoring downhole drill string $\mathrm{V} \& \mathrm{~S}$ is research priority, and reducing drill string resonance is a main purpose. Sensor installation site has drill collar and bit. In the latest stage [11-15, 5052], the measuring instrument of dynamic drilling parameter (MIDDP) is combined with the rotary steerable system (RSS) and no drilling surprises (NDS) to solve practical problems. MIDDP has been successfully developed to improve the ability to control the drilling process and reduce drilling risks.

There are several typical vibration measurement tools. A detailed view section of these tools is depicted in Figure 5 and they are the latest vibration measurement tools in the field of drilling engineering of oil industry. The extreme working conditions are as follows. The maximum work pressure of these measurement tools is $206.8 \mathrm{MPa}$ and the maximum work temperature is $-40^{\circ} \mathrm{C} \sim 180^{\circ} \mathrm{C}$. Measurement parameters contain weight on bit (WOB), torque on bit (TOB), bending stress, revolutions per minute (RPM), acceleration, annulus pressure, mud pressure, the drill bit pressure drop, and temperature. The measuring system consists of four parts, downhole sensors (speed sensors and acceleration sensor), data acquisition, underground storage, interpretation, and the ground data processing system. MIDDP can be installed on the wellhead [10,61], drill collar [62], and bit [65], or multiple sensors can be installed at the same time [12]. Inbit dynamic sensor (Figure 5(b)), BlackBox Eclipse downhole measurement tool (Figure 5(d)), and BlackBox HD downhole dynamics recorder (Figure 5(e)) are installed on the bits which can obtain the accurate vibration of bits. DDS sensor 


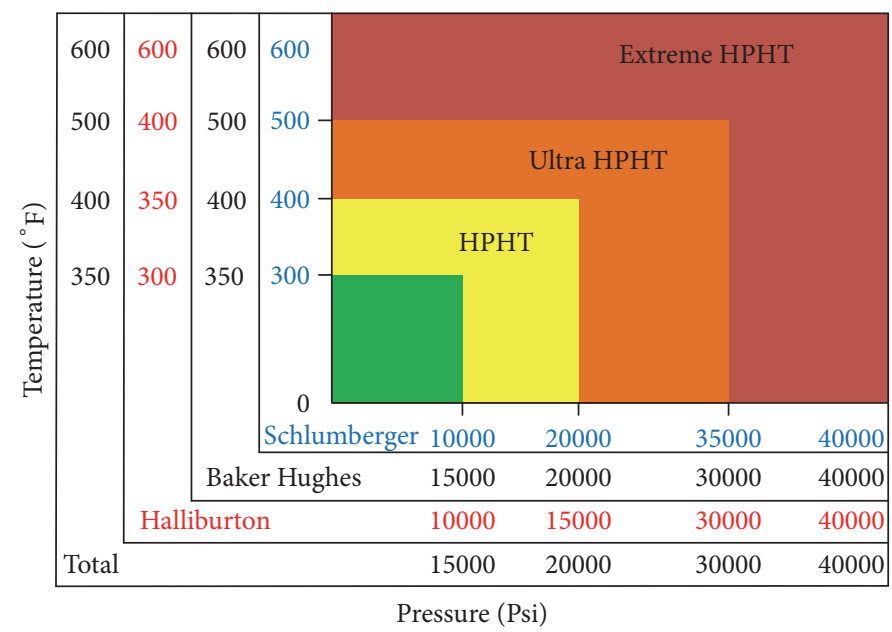

FIGURE 6: HTHP classification system.

TABLE 3: Lateral vibration level classification.

\begin{tabular}{lccc}
\hline Levels & $\begin{array}{c}\text { Axial acceleration } \\
\text { RMS (g) }\end{array}$ & $\begin{array}{c}\text { Lateral acceleration } \\
\text { RMS (g) }\end{array}$ & Limit time \\
\hline Low & $<1$ & $<1$ & No \\
Medium & $1 \sim 2$ & $1 \sim 3$ & 24 hours, suggest reducing vibration \\
High & $2 \sim 4$ & $3 \sim 6$ & 12 hours, must reduce vibration \\
Severe & $>4$ & $>6$ & 30 minutes, immediately reduce vibration \\
\hline
\end{tabular}

TABLE 4: Torsional vibration level classification.

\begin{tabular}{lccc}
\hline Level & Stick-slip $(/ \mathrm{r} / \mathrm{min})$ & State & Limit time \\
\hline Low & $0 \sim 40$ & & No \\
Medium & $40 \sim 60$ & Torsional vibration & No \\
Medium & $60 \sim 80$ & & Suggest reducing vibration \\
High & $80 \sim 100$ & Stick-slip & Completely, must reduce vibration \\
Severe & $>100$ & Stick-slip & 30 minutes, immediately reduce vibration \\
\hline
\end{tabular}

(Figure 5(a)), annular pressure while drilling measurements (Figure 5(c)), BlackBox enhanced measurement system tool (Figure 5(g)), engineering parameters while drilling tool (Figure 5(h)), and vibration memory module (Figure 5(i)) are installed on the BHA. Data acquisition method contains realtime transmission $[7,8,13]$ and downhole storage method [62]. Maximum storage frequency is $650 \mathrm{~Hz}$ [62] and maximum sampling frequency is $2080 \mathrm{~Hz}$ [11]. But the time delay problem is serious in real-time transmission. Although the real-time transmission can dynamically monitor the downhole conditions, the downhole storage method is a better way to analyze the high-frequency signals characteristics of drill string V\&C.

However, one of the key problems of measurement tools is the adaptability to the ultra-deep wells and extremely cold area; the working temperature is the key factor. The performance of these measurement tools, in comparison with the HPHT classification system [87], can adapt to the ultrahigh pressure environment, but only to high temperature environment as shown in Figure 6, which limits the measurement of drilling engineering parameters in ultra-high temperature and extreme HTHP formation. So the "drilling blind spot" of ultra- and extreme-HTHP formation has not been recognized without the true and real-time downhole drilling parameters. The research and development of MIDDP adapt to the HTHP environments which is one of the future key problems for the drill string vibration evaluation.

Another key problem of practical measuring method is the date processing of dynamic signals and establishing of evaluation criterion. Several new methods and suggestions are investigated and discussed. According to the root mean square (RMS) and the experience threshold of measured acceleration value, evaluation criteria for drill string V\&S was developed by Halliburton [7], Baker Hughes [8], APS [12], NOV, and Schlumberger $[14,15]$ as shown in Tables 3 and 4. The applicable scope of practical measuring method to evaluate the drill string V\&S levels is limited by the method accuracy, because of the fact that different oil fields have 
different stratigraphic characteristics. The practical measuring method must be based on lots of measures and analyses for the target oil field. A power spectrum density processor (PSDP) is located near the drill bit while drilling [88]. The PSD of the vibrations generated by the bit while drilling was computed by PSDP. The PSD date is telemetered to the surface, which is used to enhance drill bit seismic techniques, as shown in Table 5.

Recently, there is no unified evaluation standard for drill string to be used in oil industry. Lack of systematic research of evaluation methods for drill string V\&S is the key problem [7-15, 50-52, 61-66, 88]. However, there are many kinds of evaluation methods about seismic level [83]. In order to establish a unified evaluation method, we can learn some knowledge from the area of seismic research. The approach used for quantification of vibration-related risks was based on the indices used in geotechnical earthquake engineering to describe the destructive potential of seismic movements [83-86, 89-94]. Vibration intensity was used to objectively determine the intensity of shaking by measuring the acceleration of transient seismic waves as the time integral of the square of the ground acceleration. An estimation of the average intensity of vibrations along the run was provided by power index [86]. Acceleration root square is determined by obtaining the root square value of the plain integral of the squared acceleration [93]. Characteristic intensity was defined as a parameter related linearly to an index of structural damage due to maximum deformations and energy dissipation [84]. Real-time quantification of drill string failure risk is shown in Table 6.

$V_{\text {rms }}$ is the root mean square, $T_{p}$ is the signal's period, $V(t)$ is the time dependent signal, $g$ is the acceleration due to gravity, $a$ is the acceleration as a function of time, $I_{A}$ is the Arias intensity, and $T_{d}$ refers to total time of the bit run.

\section{Control Technology}

With increasing well depth and wide application of special trajectory technology $[4,6]$, the drill string V\&S can cause a great economic loss. A variety of control measures have been developed. According to the control theory and control engineering knowledge, the control method of drill string V\&S can be divided into passive control, active control, and semiactive control. Comprehensive induction and classification are discussed such as the typical structure of key equipment, principles and core control methods, and representative results. Comparative analysis and discussion of the key methods, the corresponding key control equipment and application ranges are carried out. Control program is formulated based on the previous research results; the future research direction of control of the drill string V\&S is discussed.

3.1. Passive Control. Passive control of drill string V\&S is that the control system did not need any external power but the energy of existing system. Early control technologies belong to passive control.
3.1.1. Preventing Drill String Resonance. Preventing resonance is the first and the most common methods of drill string passive control [24]. The main contents include establishing a mathematical model, solving the inherent frequency, and conducting modal and harmonic analysis. This method focused on the optimizing drilling parameters and changing the BHA structure in order to avoid the resonance frequency of drill string.

Lots of researchers have focused on the solution of natural frequency and optimizing drilling parameters of drill string. The trial and error method to solve approximate natural frequency of drill string was studied by Finnie and Bailey [69]. The frequencies of torsional and longitudinal vibrations were observed, but the effect of damping was not considered in the method. The differential equation of torsional vibration was established by Aarrestad et al. [44]. The differential equation assumed that rotary table was fixed, bit was free, and the torsional vibration frequency had nothing to do with RPM, WOB, and damping. The effect of BHA length on the drill string vibration was focused by Huang and Dareing [95]. It is noted that the method in this paper can determine the natural frequency of the lateral vibrations of long vertical pipe subjected to end thrust loads. However, this method cannot be used to the horizontal well. Therefore, the transversal vibration of drill string contacting with the borehole wall in horizontal well was studied by Heisig and Neubert [41]. The analytical solution for the threshold rotary speed has been derived and is verified using the finite element model. It is remarked that a drill string in a horizontal borehole can vibrate in a snaking or in a whirling mode. A rigid model of drill string was proposed by Menand et al. [96]. Where the helical buckling critical load of rotating drill string was about $50 \%$ of nonrotating drill string. The lateral vibration equation and the buckling critical equation of drill string were derived by Wang [42]. The equation takes into account the effect of flow inside drill string, but the equation cannot be verified in the field of drilling engineering. A natural frequency calculating model of drill string vibration was developed by $\mathrm{Qu}$ et al. [97], where the effects of fluid flow and temperature were considered. It is noted that the increase of fluid flow rate in the wellbore can induce the instability of the lateral vibration of dill string. The BHA backward whirl using the rotor dynamic theory was analyzed by Yucai and Zhichuan [34]. The theory model was verified by the indoor model test. Optimizing drilling parameters of dynamic is also a good way to prevent drill string resonance. The relationship of WOB, RPM, and vibration for PDC bits was summarized by $\mathrm{Wu}$ et al. [59] as shown in Figure 7. The optimum zone is defined as a closed domain in the space of WOB and RPM. The drilling parameters in the optimum zone theoretically guarantee stability. The scope of the optimum zone depends on the bit and the rock to be drilled. Real-time optimization of drilling parameters by combining the monitoring vibration data was carried out. The stability map of high-frequency torsional vibration in the field was summarized $[98,99]$ as shown in Figure 8, which provided a basis for controlling the drill string V\&S. The low and high amplitude vibrations distinctly fall into zones, which indicate that high-frequency torsional vibration occurs at higher WOB and low RPM. 


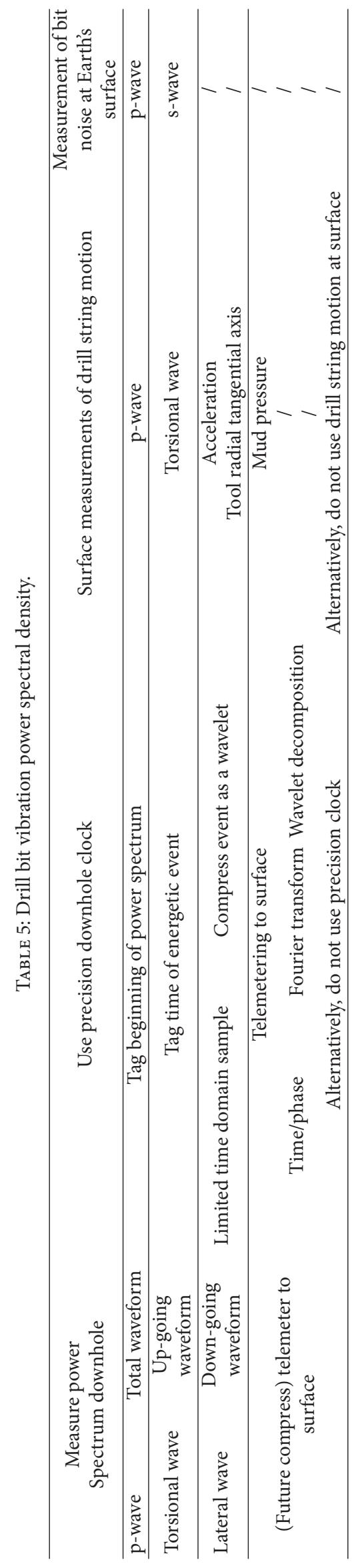


TABLE 6: Real-time quantification of drill string failure risk.

\begin{tabular}{|c|c|c|}
\hline Name of equation & Equation & Units \\
\hline Root mean square [83-85] & $V_{\mathrm{rms}}=\sqrt{\frac{1}{T} \int_{0}^{T_{p}} V(t)^{2} d t}$ & g \\
\hline Vibrations intensity [86] & $I_{A}=\frac{\pi}{2 g} \int_{0}^{T_{d}} a(t)^{2} d t$ & $g^{2} h$ \\
\hline Acceleration root square [83] & $a_{\mathrm{rs}}=\sqrt{\int_{0}^{I_{d}} a(t)^{2} d t}$ & $\mathrm{~h}^{0.5} \mathrm{~g}$ \\
\hline RMS acceleration [83] & $a_{\mathrm{rms}}=\sqrt{\frac{1}{T_{d}} \int_{0}^{T_{d}} a(t)^{2} d t}$ & $\mathrm{~g}$ \\
\hline Power index [86] & $P_{a}=\frac{1}{T_{d}} \int_{0}^{T_{d}} a(t)^{2} d t$ & $\mathrm{~g}^{2} / \mathrm{h}$ \\
\hline Characteristic intensity [84] & $I_{C}=a_{\mathrm{rms}}^{1.5} t_{d}^{0.5}$ & $\mathrm{~g}^{1.5} \mathrm{~h}^{0.5}$ \\
\hline Peak acceleration [83] & $a=a_{\text {peak }}$ & g \\
\hline
\end{tabular}

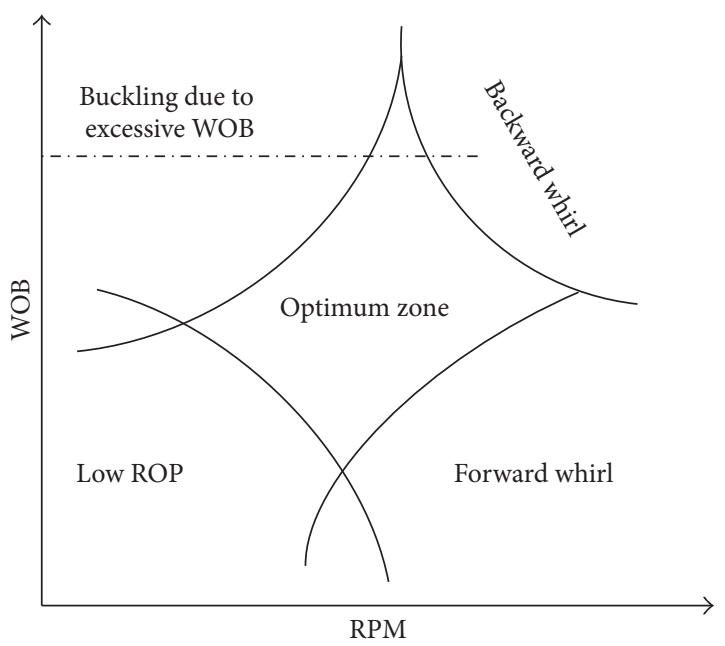

FIGURE 7: The relationship of WOB, RPM, and vibration for PDC bits.

The right "drilling dessert (optimum zone)" within a certain range can be found by optimization drilling parameters; optimization drilling parameters only solved the vibration sources frequency and nature frequency of drill string. However, the drilling efficiency could be reduced by excessive adjustment of drilling parameters. Calculating the drill string natural frequency and vibration mode using the mathematical model was a usual and simplified method, but it is difficult to get accurate inherent features; the drill string V\&S could not be completely eliminated. Optimizing BHA to change the natural frequency of the drill string is another well approach to suppress the drill string V\&C.

Commonly used method of optimizing BHA is adjusting the quantity and site of stabilizer or reamer. Shear stress along the BHA and the bit had greater volatility which was found by Bailey et al. $[35,57,100,101]$. It is remarked that there were torque mutations in the stabilizer, and the stabilizer was a main cause for the BHA backward whirl and stickslip vibration. There are two new improvements on new BHA structure as shown in Figure 9. The near-bit stabilizer of drilling tools was removed; roller reamer was moved to the heavy wall drill pipe (HWDP). According to the statistical analysis of RasGas and ExxonMobil [57, 101], the transverse vibration and stick-slip of the drill string can be controlled by new BHA. The average ROP and total footage were increased by $36 \%$ and $36 \%$, respectively. New BHA was conductive to the ultra-deep well and gas drilling. The method can be used to the PDC bits and roller bits and hybrid bits.

\subsubsection{Changing Energy Distribution of Drill String. Energy} distribution was changed from the boundary condition of drill string system. Bit mainly changed the magnitude and forms of axial input force, and the stabilizer and reamer changed the drill string lateral contact with the borehole wall including distance and contact force between the drill string and the borehole wall.

First of all, the input energy of vibration source was reduced by the use of antivibration bit. The antivibration bit with special structure design can suppress or mitigate the vibration amplitude of drill bits as shown in Figures 10 and 11. The bit-rock interaction caused axial vibration and stickslip vibration, where this dynamic energy was transferred to the drill string system, so the bit was the main source of drill string V\&S. The excitation source contained RPM, bit/rock interaction, mud pump, and stabilizers [102]. The theory study of changing energy distribution focuses on the effect of bit structure and bit type to the dill string V\&S. The effect of tricone bit random vibration on the drill string longitudinal vibration was studied by Skaugen [103]. The model can be used to predict sharply increased vibration amplitudes when rotary speed is a certain subharmonic of resonance frequencies in the drill string. It is noted that there are axial and rotational quasirandom components, both for axial and for rotational movement. A coupled vibration model of drilling string was analyzed by Yigit and Christoforou [58]. The model considers the effect of axial, lateral, and torsional vibration and quantitatively describe the effect of PDC bit-rock interaction on the drill string vibration. The phenomenon of bit whirl was studied by Sinor et al. [33]. The antiwhirl bit was firstly developed with smooth edges and reasonable cutter layout, but the bit just considers the basic bit design. The well deviation was affected by the bit whirl and stick-slip, and the concept of "flexible bit" was proposed [104]. A flexible connector was installed on the cutting teeth of bit in order to reduce bit deviation. However, the flexible PDC bit was not applied to the field due to the failure of flexible connector. Based on the response law of bit eccentric motion, a new design method was proposed by Johnson [105], by which eccentric PDC bit increased the centripetal force and reduced side cutting force and transverse vibration. Detailed configuration of the two-core PDC bit is presented in Figure 10(a). A new thermostable PDC bit to reduce bit vibration was developed by ExxonMobil and Schlumberger $[106,107]$. The structure of the PDC bit is depicted in Figure 10(b). There were some notable features about the PDC bit: (1) 6 blades and $16 \mathrm{~mm}$ cutter preferable; (2) tooth and auxiliary tooth structure in each blade; (3) tapered structure used. The structure reduced friction force of bit and the friction force is the main reason of drill string dynamic instability. The advantage of this design is making full use of the optimizing structure and the thermostable 


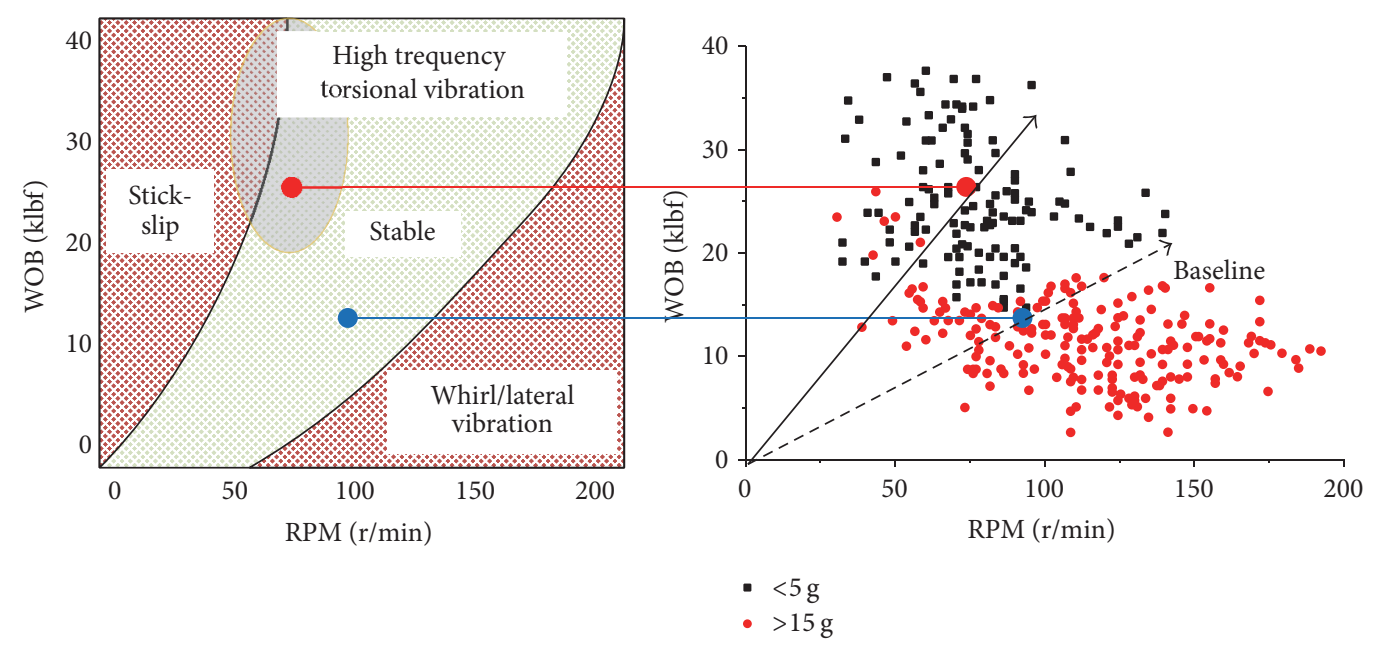

FIgURe 8: A typical stability map for PDC bits.
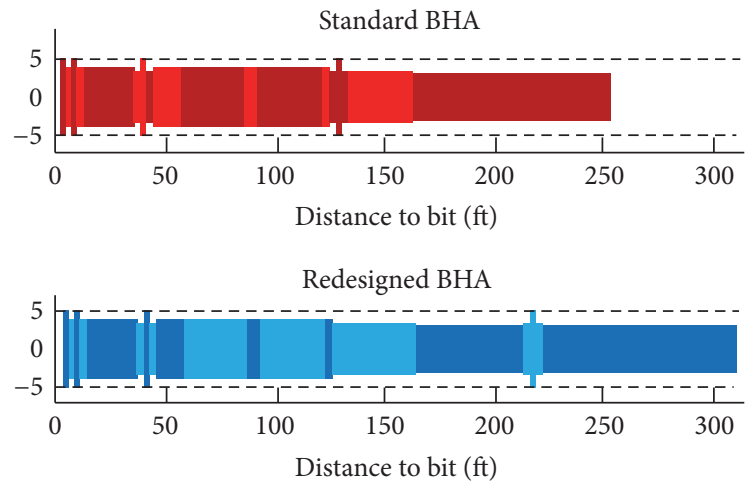

Figure 9: Configurations for the standard BHA and redesigned BHA.

ability. But its disadvantage compared with the two-core bit is the poor ability of mitigating the vibration of drill string. A new hybrid bit was produced by Baker Hughes [108]. The hybrid bit takes advantage of the high WOB ability of cone bit and the high ROP of PDC bit. Three basic hybrid bit designs are presented: a two-cone, two-bladed version for smaller-diameter bits, a larger three-cone, three-bladed version for larger diameters, and a three-cone, six-bladed version. A detailed view section of this mount is depicted in Figure 10(c). They are based on proven four- and sixbladed PDC bit designs in which the secondary blades have been replaced with truncated rolling cutters. The hybrid bit can drill significantly faster than a comparable roller cone bit in the field applications. Another benefit is the effect of the rolling cutters on the bit dynamics. Compared with conventional PDC bits, torsional oscillations are as much as $50 \%$ lower, and stick/slip is reduced at low RPM and whirl at high RPM. A new PDC bit to eliminate stick-slip was developed by Schwefe et al. [109]. The configuration of this bit is shown in Figure 10(d) which can reduce the TOB by controlling the fixed depth-of-cut (DOC) control part.

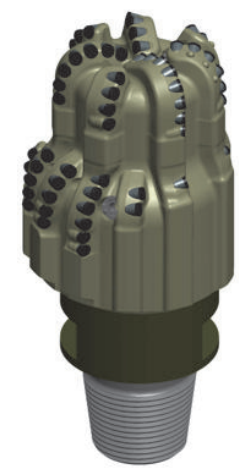

(a) Two-core bit

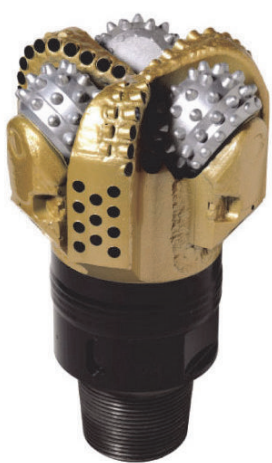

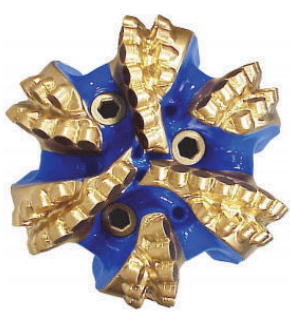

(b) Antivibration bit

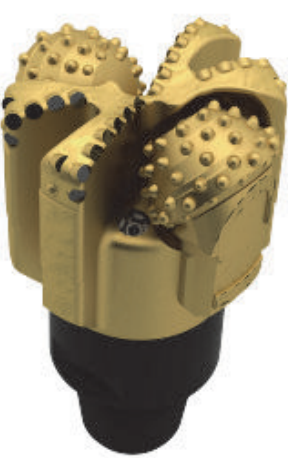

(c) Hybrid bit

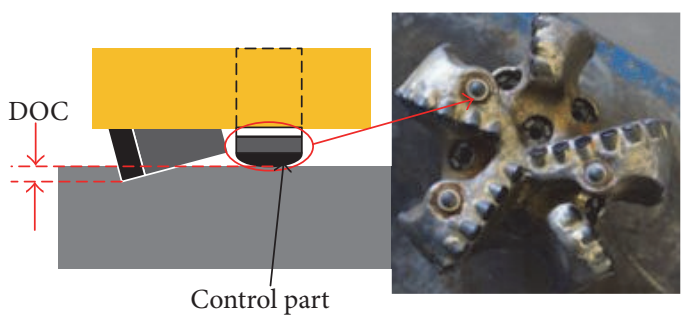

(d) DOC bit

FIgURE 10: Typical suppression vibration bit. 


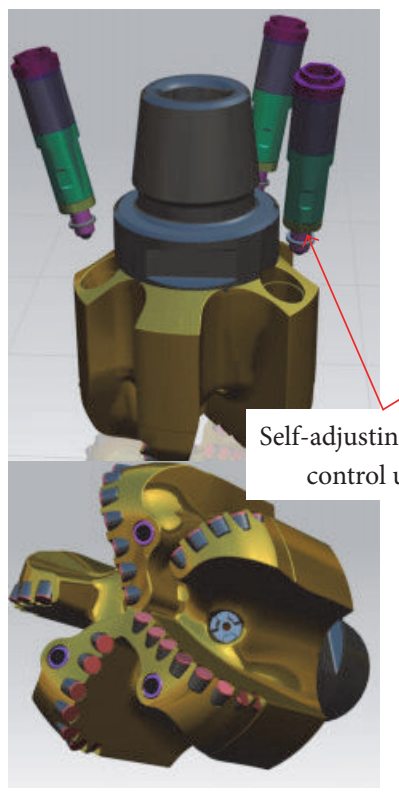

(a) The self-adjusting PDC bit
Enables gradual change in DOC

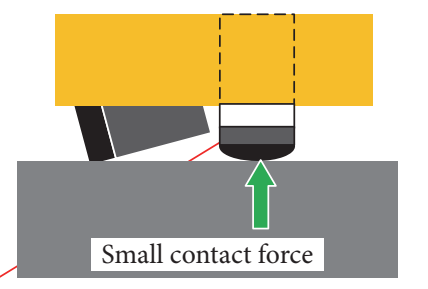

Resists sudden change in DOC
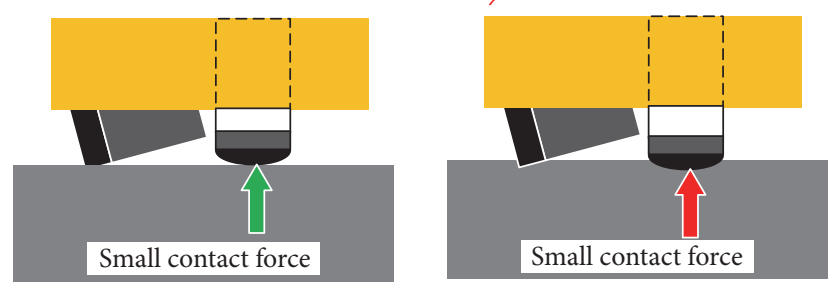

(b) The concept illustration of self-adjusting DOC control

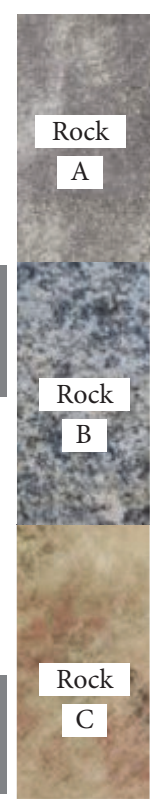

FIGURE 11: The self-adjusting PDC bit and concept illustration.
Comparing to the standard cutter without DOC unit, the new bit with the DOC unit limits the loading of high WOB to reduce the indentation depth of PDC cutters. The design concept is easy to come true. However, the drilling industry faces the task of drilling different rock type in one well with a single bit; the PDC bit with fixed DOC control (DOCC) elements limit vibration mitigation and the increase of ROP. Hence, an innovative PDC bit with self-adjusting DOCC elements was proposed by Schwefe et al. [110], which can selfadjust its DOCC ability to the constantly changing drilling environment and mitigate $\mathrm{V} \& \mathrm{C}$ while delivering improved ROP. The detailed structure of this new concept PDC bit is in Figure 11(a). To illustrate the concept, a hypothetical formation with three rock types is considered as shown in Figure 11(b). Sections B and C are prone to stick-slip. The PDC bit with fixed DOCC elements requires offset well data to drill the well which limit the ROP and ability of mitigating stick-slip. The PDC bit with self-adjusting DOCC units offers an elegant solution to resist the DOCC fluctuation at the time scale of stick-slip in rock $B$ and rock $A$. the gradual retraction of DOCC units enables faster drilling in the soft rock A. The advantage of the bit is anticipated to absorb shocks in interbedded formations.

The second approach was the use of decoupled or adjustable reamer in reaming operations. Roller reamer could decouple stick-slip and the whirl of drill string [111]. The configuration of the reamer is shown in Figure 12(a), because the friction force between roller and borehole wall was small. Roller reamer made wellbore more smooth, and repeat reaming reduced the bending moment and $\mathrm{TOB}$ of $\mathrm{BHA}$. When a reamer was installed in the drill string about $40 \mathrm{~m}$ from the bit, the borehole could have better quality. The advantage of roller reamer is not only suppressing the lateral vibration and torsional vibration at the same time but also reducing the friction between the drill string and borehole wall. The fixed stabilizer installed on the reamer could not stabilize the upper drill string, which aggravated the drill string V\&S [112]. A new expandable reamer to mitigate drill string V\&S was developed by Schlumberger and Baker Hughes [59] and its configuration is depicted in Figure 12(b). The reamer was expanded to support the borehole wall, and then the drill string had small bending and amplitude of V\&C. The field test of expandable reamer was carried out in Oklahoma; the test results show that when the well deviation is less than $30^{\circ}$, the ROP increased by $35 \%$. When the well deviation is less than $20^{\circ}$, the transverse vibration and whirl of the drill string were reduced by $26 \%$. The effect of suppressing vibration of expandable reamer used with dual core bit is better. There are some characteristics and advantages: (1) Each blade has two rows of cutting tooth, with the purpose of strengthening the ability of wear-resisting. (2) Gauge pad can reduce the dogleg angle of well trajectory and drill string. (3) Replaceable protection and stability block can avoid stress concentration due to welding heat effect. However, compared with roller reamer, expandable reamer mainly control the lateral V\&C.

Another effective method for controlling V\&S was the stabilizer installed on the drill string. Based on the study of Dareing [24, 72, 95], longitudinal and torsional vibration response of drill string depended on viscoelastic damping and support constant $[36,53]$. The dynamic response can lead to chaotic movement of drill string. A new Vshaped stabilizer for stick-slip and whirl of coiled tubing operation was developed by National Oilwell Varco (NOV) [113]. Detailed configuration of the stabilizer is presented in Figure 13(b). Two pieces of stabilizer blade were shaped like a 


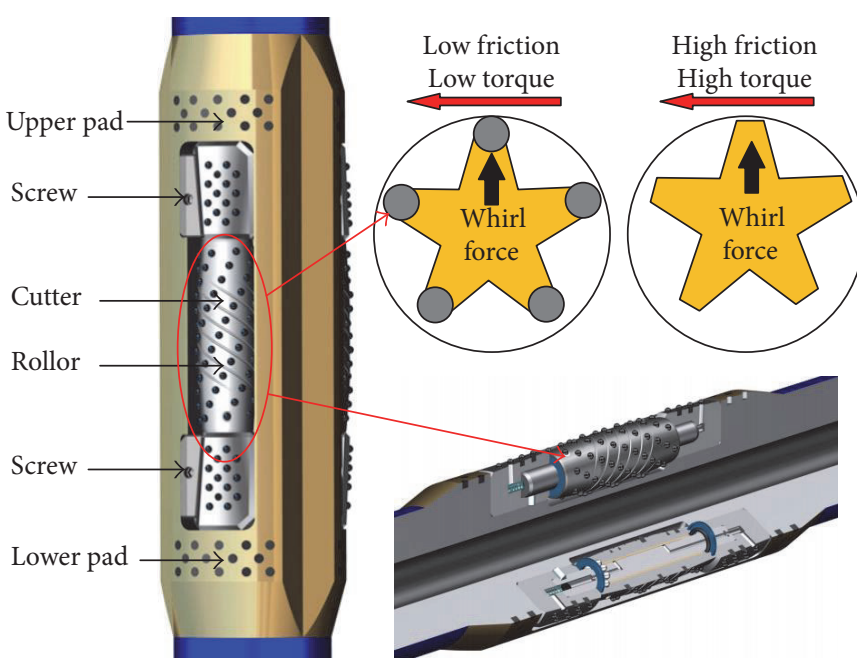

(a) Roller reamer

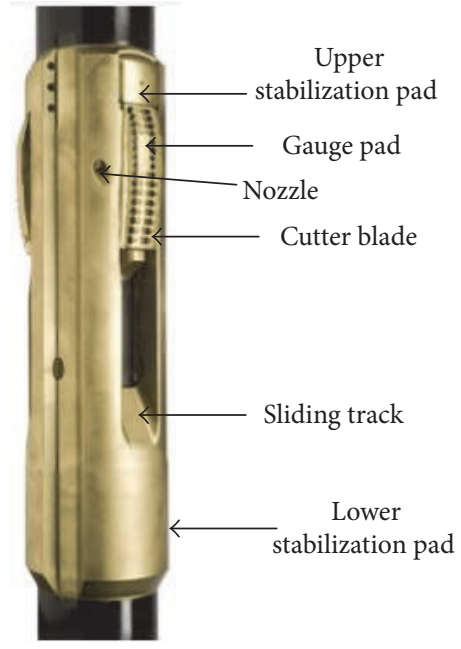

(b) Expandable reamer

FIgURE 12: Typical vibration reduction reamer and concept illustration.

nonaxisymmetric structure, and the core working principle is the centrifugal force of drill string rotary. When the vibration was transmitted to the stabilizer, the vibration mode was eliminated. The V-shaped stabilizer can induce drill string forward whirl (FSW) to improve ROP for the first time. The test results of V-shaped stabilizer in the Green Canyon section of the Gulf of Mexico show that ROP increased by more than $50 \%$, and stick-slip decreased by more than $75 \%$. The downhole tool drop can be prevented by integrated design of the stabilizer. A new expandable stabilizer was proposed by Al-Thuwaini [37, 38]. The detailed structure of the expandable stabilizer is shown in Figure 13(a). The expandable stabilizer is an improvement of the expandable reamer. The main difference is that the cutting tooth of expandable reamer was replaced by the stabilizer blade. The sharp edge of stable blocks with double inclined plane radial distribution improved ROP. A new near-bit stabilizer was developed by NOV [114]; the configuration of the bit is shown in Figure 13(c). This stabilizer with four spiral blades was divided into the totally enclosed type and the semienclosed type. Fully enclosed structure could control vibration of drill string and improved the signal-to-noise ratio (SNR or S/N) of bit. SNR is a measure used in science and engineering which compares the level of a desired signal to the level of background noise and is defined as the ratio of signal power to the noise power. Semiclosed structure was conducive to the cuttings carrying and hydraulic parameters optimization. Back pressure valve and vibration monitoring instrument were installed on the stabilizer. Compared with the V-shape stabilizer and expendable stabilizer, the advantage of the bit is that the simple structure makes full use of the ability of mitigating vibration and cuttings transportation.

The forth method was passive control of deep water riser. Changing surface shape of the riser will change the flow field around the structure, which could decelerate the formation, development, and peeling process of vortex [54]. Passive control methods for controlling VIV were divided into three types [55]. The first type is the interference entrainment layer of vertex such as ribbon fairing. The second type is the interference of separation line or separating shear layer such as axial bar, blade, and half spherical structure. The third type is the effect of entrainment layer wrapped such as pipe sleeve, screen structure. Currently the successful development and application are spiral stripe suppression structure as shown in Figure 14(a) and the fairing structure as shown in Figure 14(b) [56].

Means to change energy distribution were economic, effective, and simple, but the friction force of drill string will be increased by this equipment. Protecting the important equipment and the smooth work of the drill string is another effective method.

3.1.3. Shock Absorber Balances the Dynamic Energy System of Drill String. The shock absorber is one of the most effective passive control methods, divided into axial ones and rotational ones. The peak value of the drill string V\&S depended on the damping caused by mud and drill pipes [115]. Two kinds of axial absorber are widely used in drilling engineering. One kind is disc spring shock absorber; the detailed structure of shock absorber is shown in Figure 16(a). The optimal compression stroke is $10 \%-75 \%$ of the maximum compression stroke. When the WOB is too high, the compression spring will absorb one part of WOB. With the decrease of WOB releasing energy to the bit, drill process will be always smooth. The shock absorber close to the bit controlled severe vibrations and extended the service life of bit. The expensive equipment was protected by the shock absorber installed below the MWD and LWD. The connector body strength of absorber can withstand ambient temperature of $231^{\circ} \mathrm{C}$ and a work time of 300 hours. The absorber is suitable for directional drilling, hard formation, horizontal drilling, casing side tracking window, borehole reaming, and coiled tubing operations. The other axial absorber is hydraulic shock 


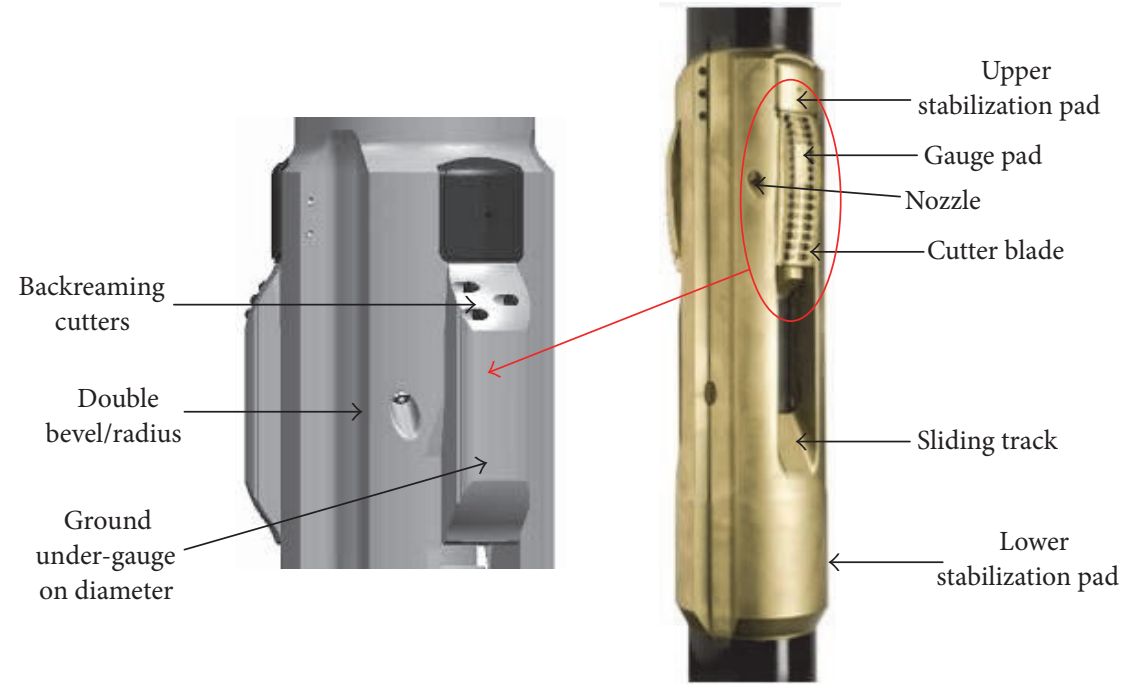

(a) Expandable stabilizer

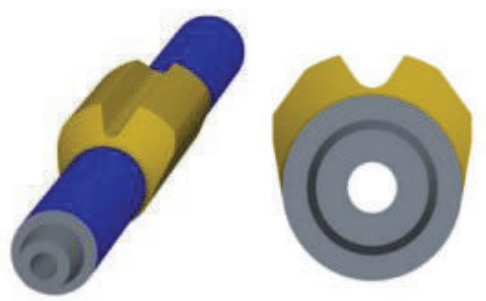

(b) V-shape stabilizer
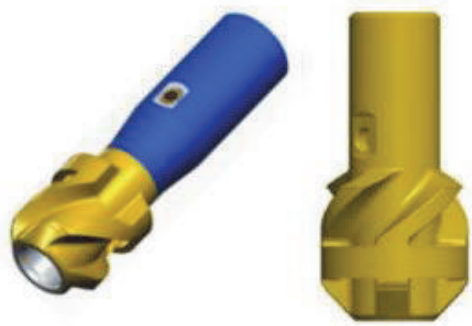

(c) Antivibration near-bit stabilizer

FIgURE 13: Typical vibration reduction stability.

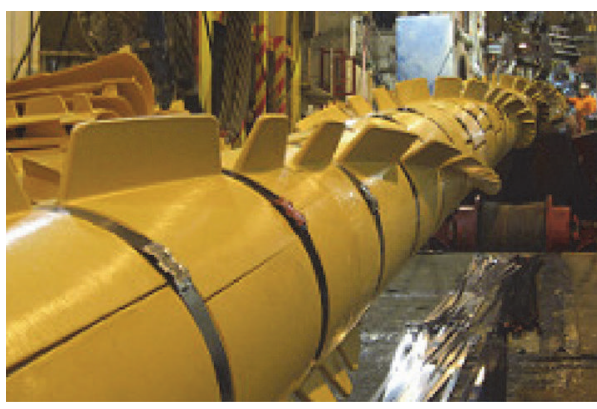

(a) Spiral band control device

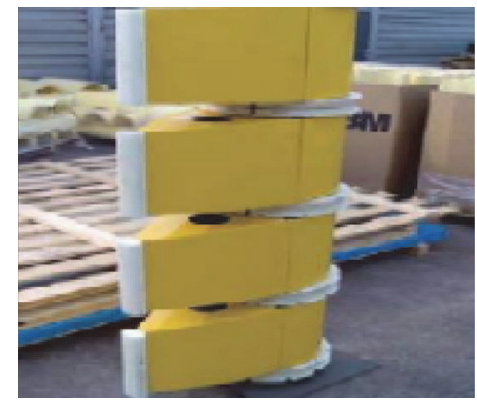

(b) Fairing control device

Figure 14: Typical deep water vortex-induced vibration controller.

absorber. The configuration of the absorber is in Figure 15. The control principle of drill string V\&C is similar to the disc spring shock absorber. The structure of the hydraulic shock absorber to balance the dynamic energy system of drill string is hydraulic oil. Compared with the disc spring shock absorber, the bearing capacity of hydraulic shock absorber is large. A new rotational vibration absorber (antistall tool) for deep hard formation and interaction formation of bit stickslip was developed by Seines et al. [116] and its configuration is depicted in Figure 16(b). The core working principle is that
TOB was converted in the compression energy of torsional spring to reduce the torsional vibration. An abrupt increase in torque $\left(M_{2}\right)$ will cause a telescopic contraction $(S)$ to offload the weight from the cutters $\left(F_{2}\right)$. The concept illustration of AST is in Figure 17. For anti-stick-slip tool (AST/antistall tool) installation position [117], it is close to the bit as far as possible; in order to meet the demand of RSS and sensor measurement, AST was often installed above the MWD and the reamer. According to the statistics [117], the test results in Azerbaijan show that total footage and ROP utilizing the AST 


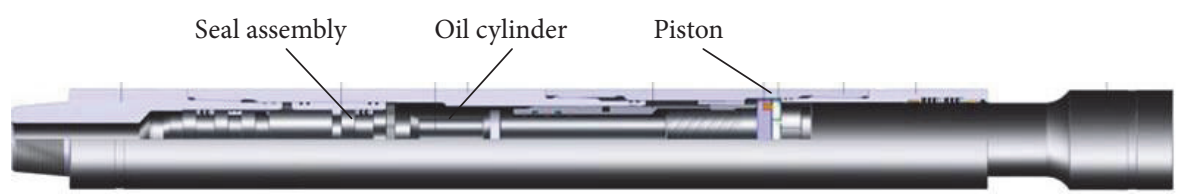

FIGURE 15: Hydraulic shock absorber.

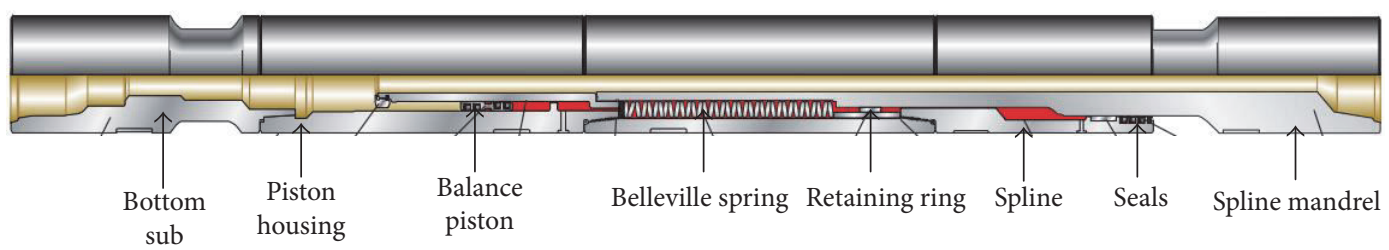

(a) Axial absorber

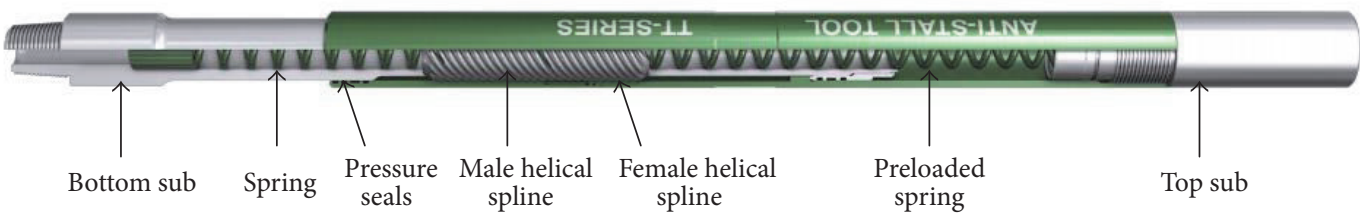

(b) AST absorber

Figure 16: Typical V\&S absorber.

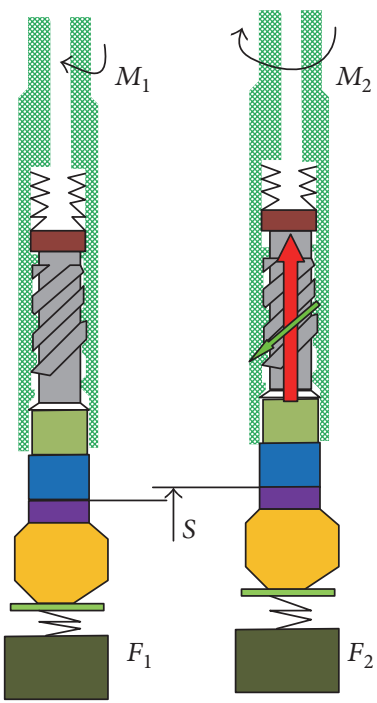

FIGURE 17: The concept illustration of AST.

increased by $15 \%$ and $40 \%$, respectively. Severe vibration time decreased by $46 \%$. Compared with the axial absorber, the advantage of AST controls the torsional vibration and axial vibration to mitigate the stick-slip.

Although this passive control method to reduce the drill string V\&S is simple and economic, the control of shock absorber is limited. Because of the complex V\&S on the drill string, engineers and researchers should propose a method with a wide range of control and flexible adjustment capacity.
3.2. Active Control. According to the dynamic characteristics of the control system, the active control of the drill string V\&S is by active application of force in an equal and opposite fashion to the forces imposed by external vibration. The active control of drill string can be divided into the wellhead control, the bottomhole control, and the whole drill string control. Common methods include frequency methods and root locus methods. For active control of drill string, the drill string model and external interference should be considered, such as RPM, WOB, and damping. According to the relationship between the input and output of control system, the drill string system can be divided into open-loop and closed-loop feedback control systems. Open loop control is to reduce or eliminate extraneous force (WOB or RPM). Closedloop control is to change the stiffness and damping of the drill string. Recently, vibration amplitude was reduced by automatically adjusting the TOB and RPM is an important method.

An active damping strategy of stick/slip vibrations was developed by Jansen et al. [45], which was realized either by emulating a passive absorber behavior or by using a more advanced (typically state-variable) drill string speed controller structures. The passive absorber behavior was described with rotational spring and damping coefficient. Indirect approaches are typically based on a WOB control system coupled with the main RPM controller. An inputoutput type $\mathrm{HN}$ controller for practical applications was proposed by Serrarens et al. [118], but it is not quite clear from the presented results if such a constant-parameter high-order controller can provide consistent performance for a wide range of drill string lengths and configurations. 


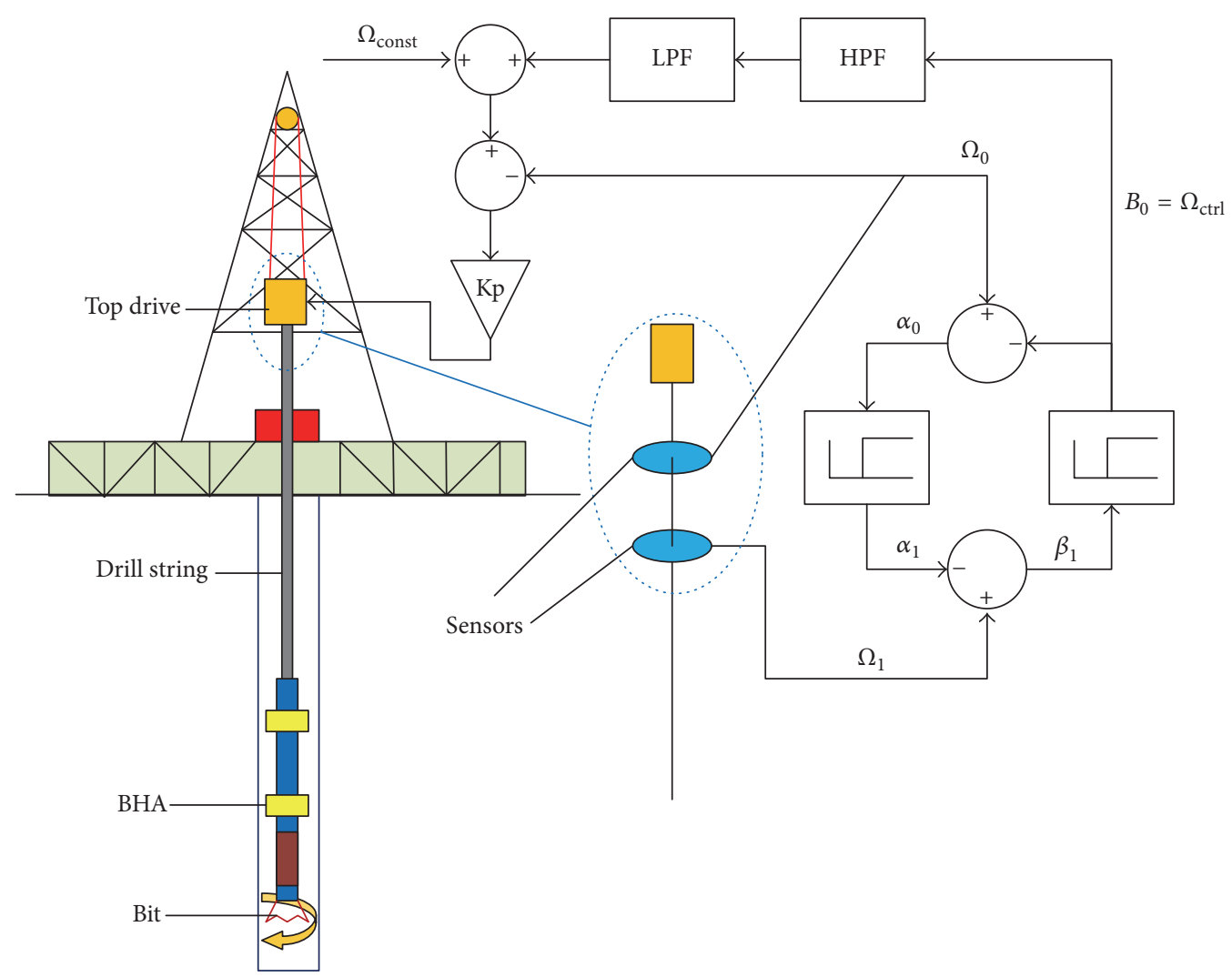

FIGURE 18: Controlling torsional vibrations of drill strings via decomposition of traveling waves.

A proportional-integral (PI) speed controller based on the spatial distribution model of drill string was designed by Tucker and Wang [46]. However, the low order controller was difficult to completely control the torsional vibration. The coupled torsional and lateral vibration were eliminated by the use of the state feedback controller [60]. A method for handling a stuck tool situation was proposed by means of a state controller with a WOB feedforward action [119], but it does not consider the braking power and torque saturation effect. A single input-output closed-loop control system (DOSKIL) was established by Canudas-de-Wit et al. [120], which was verified by the indoor experimental model. A stick-slip control model based on the error compensation method was proposed by Puebla and Alvarez-Ramirez [121], where the cascading and distributed control framework were derived; the analog results can effectively control the uncertain factors and instability of the system caused by friction. A stick-slip control model based on the GA algorithm was developed by Karkoub et al. [47], which combined the lead lag and proportional-integral-derivative (PID) controller. Based on the integrated controller, the drill string stick-slip was controlled by Majeed et al. [122]. The linearization of nonlinear system allows the pressure fluctuation to have errors, and the analog results were ideal. A full-order state controller based on the two-mass elastic process model was proposed by AlHiddabi et al. [123], but the "critical" aspect of robustness of full-order nonlinear state estimation in the presence of unknown stick-slip friction is not considered. A PID controller based on the stable stick-slip model was designed by Abdulgalil and Siguerdidjane [124]. Controller sensitivity was evaluated in connection with process parameters variables. The full-order state feedback method and full-order estimate method were unstable in the practical application. A whole drill string control strategy based on adaptive Kalman filter estimating drill string nature frequency was proposed by Pavković et al. [125], and the backward whirl of drill string caused by the braking power of servomotor was studied. A torque feedback PI motor speed controller for the drill string was developed by Deur et al. [126]. The controller has a high response speed for low inertial load tools. A state observer was used to assess the drill string torque disturbance variables. The controller and viewer were reconciled according to the damping optimization criterion based on amplitude. An adaptive PID control strategy was designed by Li et al. [48]. The control strategy is suitable for the drill string stick-slip. Kreuzer and Steidl [73] presented a method for controlling stick-slip vibrations by exactly decomposing the drill string dynamics into two waves traveling in the direction of the top drive and in the direction of the drill bit. A detailed view of this system is depicted in Figure 18. The decomposition is derived from the wave equation governing the string vibrations and is achieved with only two sensors that can be placed directly at the top drive and at a short distance below the top drive (e.g., $5 \mathrm{~m}$ ). Therefore, downhole measurements along the string and at the bit are not necessary, which is a major advantage compared to other control concepts for drill 


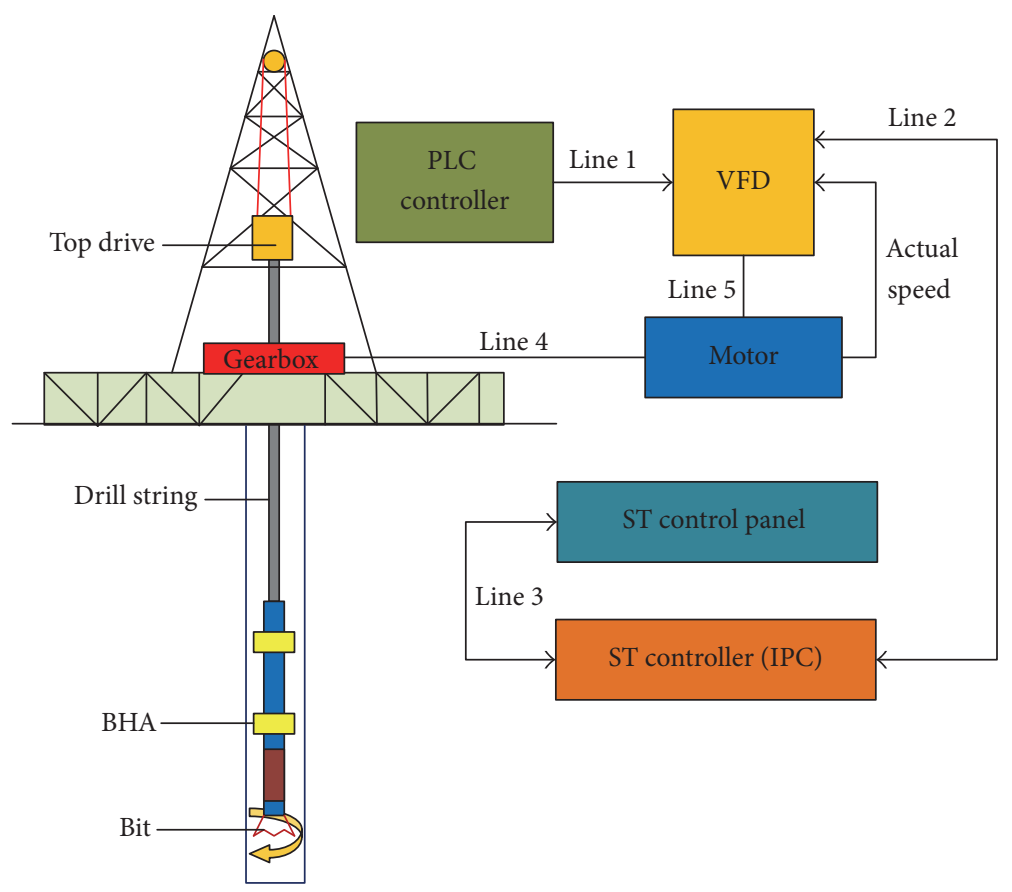

FIGURE 19: Soft torque rotation system configuration.

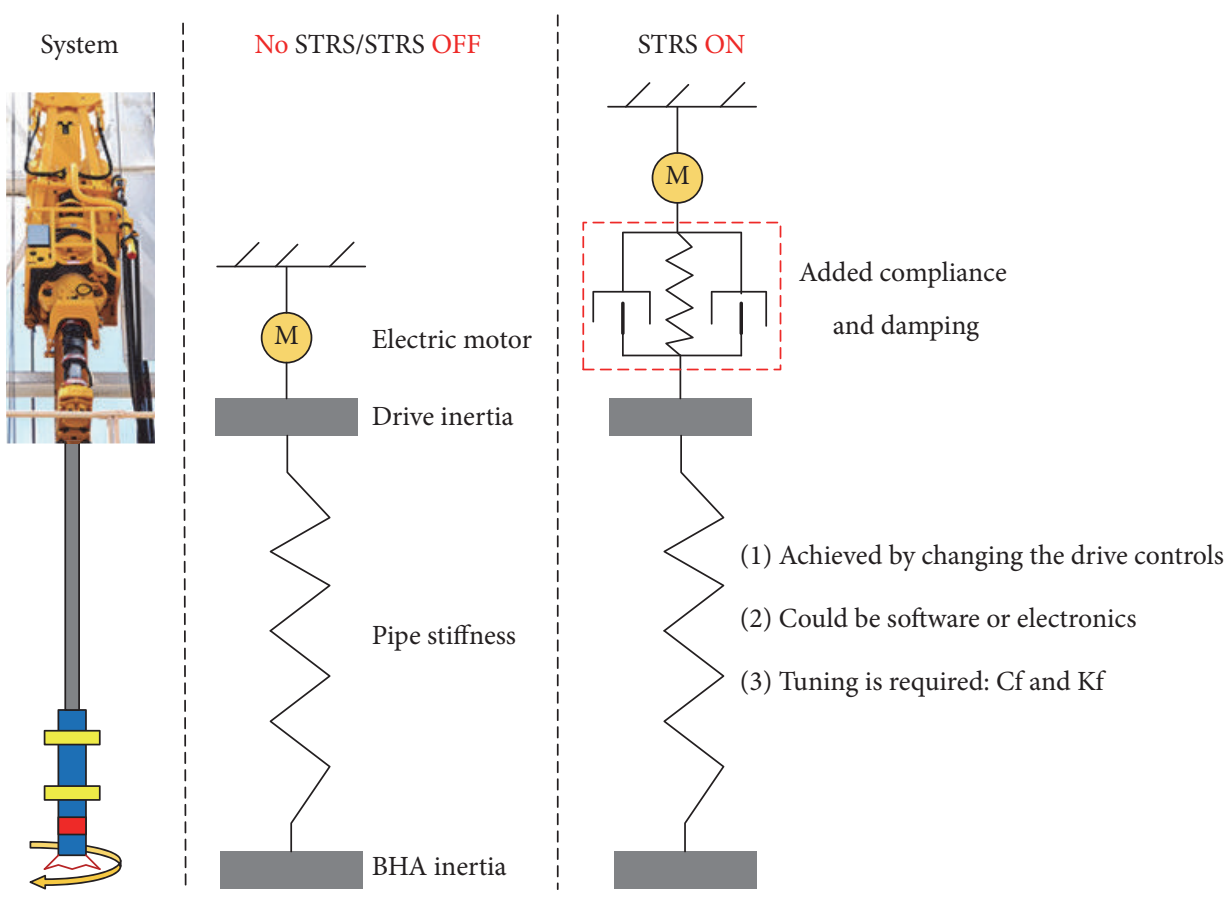

FIGURE 20: The STRS working principle.

string dynamics. A linear quadratic controller for the stickslip vibration was established by Sarker et al. [127], which was compared with spring damping vibration isolator. Based on the ellipsoid method, the neutral delay comprehensive closed-loop control model for coupled axial and torsional vibration was proposed by Saldivar and Mondié [128]. The model was verified by the results of numerical simulation. A soft torque rotation system (STRS) for the torsional vibration of drill string was developed by Javanmardi and Gaspard [129]; the active control system is the only available system for the engineering conditions. The detailed configuration and working principle of STRS is in Figures 19 and 20. The STRS was installed in the top drive, and the torsional vibration was controlled by DC motor or AC motor. The STRS introduces 


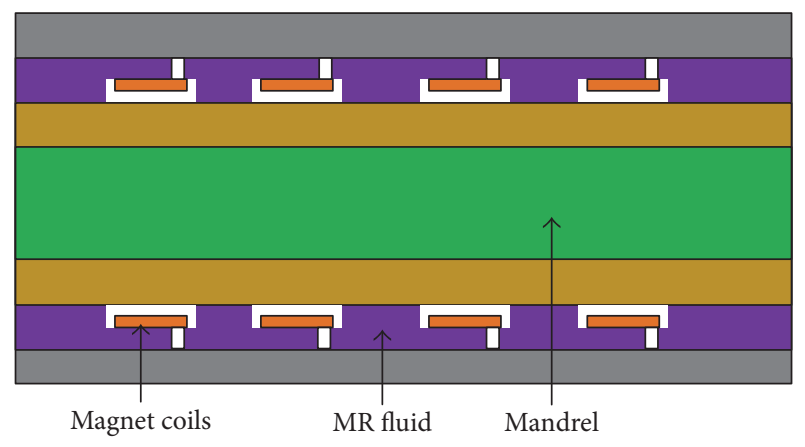

FIGURE 21: Semiactive vibration dampers.

compliance and damping in the top drive to remove torsional vibration energy instead of allowing it to build into stick-slip.

Controller of drill string V\&S was developed based on the classical control theory. The simulation results were good, but it was hard to get the accurate downhole vibration date. Calculation method of controller is complex; hardware development is difficult. Wellhead closed-loop control system had the features of fast response and low cost but could not reflect the real transmission law of the bottom hole vibration signals. The delay time of system response is longer, and calibration is difficult. Therefore, semiactive control method is another excellent solution to eliminating the drill string V\&S.

3.3. Semiactive Control. The semiactive control technology has the advantages of passive and active control. In order to adapt to the optimal state of the structure, semiactive control using passive control devices only needs less energy to change the parameters of the passive control system and working state. A semiactive vibration control damper (AVD) was developed by APS [130]. The axial and torsional vibrations can be effectively reduced by AVD. The tool chamber is filled with magnetic fluid [131, 132]; the configuration of the tool is shown in Figure 21. Drill string vibration signal given was returned to the solenoid control device, and V\&S were controlled by increasing the viscosity damping of magnetic fluid. Recently, this semiactive control found application in the field, because of the limited ability of passive control and the time delay of conventional active control from the bottom hole to the surface. Many server drill V\&C lost the best opportunity to be controlled. An approach for mitigating downhole $\mathrm{V} \& \mathrm{C}$ is to continuously monitor dynamic downhole forces and BHA motion and to intermittently transmit the most recent vibration information to the driller as shown in Figure 22(a). The driller then makes adjustments to surface control parameters whenever excessive shock or vibration levels are observed. Therefore, an intelligent selfadapting damper in the BHA without the driller's decision to frequently mitigate the drill V\&C is necessary. The system is shown in Figure 22(b). The AVD can use a part of selfadapting BHA V\&C system.

3.4. Comprehensive Comparison Analysis and Discussion of Control Technologies. Different control methods based on the widely known theories are summarized. One kind of V\&S has different control equipment and control system. Different forms of vibration or shocks can use the same equipment. But each device and system has its own limitations. Comparative analysis of the key methods, the corresponding key control equipment, and the application range is carried out as shown in Table 7. The control program of drill string V\&S is set out (as shown in Figure 23) based on existing research results, which can provide the guide of "harmless" drilling for field drill engineers. The program of drill string V\&S contains several important segments, such as optimization of drill parameters, real-time monitoring of vibration (Table 2), evaluation of vibration levels (Tables 3 and 4), and distinguishing vibration types (Table 1) and control methods (Table 7) for different vibration type and levels.

Control technologies for drill string V\&S have made some achievements and have achieved initial positive results. The passive control technology of drill string V\&S is mature, especially for axial and transverse vibration. The torsional vibration control technology was at the stage of experimentation. The control methods for axial and transverse vibration were established. Theoretical model of passive control is simplified, but not systematic. Theory results vary widely with practice results. Key equipment performance is not stable. The best parameter or new parameters by taking into consideration many comprehensive factors need to be found, which is to optimize the working performance of the key equipment. In order to give full play to the role of different types of the shock absorber, the control and optimization model of shock absorber should be established. The design of number and position fully considers the performance of the shock absorber (stiffness, natural frequency, and damping) and meets the standards for qualified transfer coefficient and reduction efficiency. The development of viscous materials is the next research focus of shock absorber. Other equivalent damping force can be used to deal with drill string V\&S.

Active control theory and simulation technology of drill string V\&S are relatively mature. The semiactive control has preliminary application. During the application process of control theory, the problem of drill string stability still has not been completely resolved. Namely, the complex motion and signal transfer law along the drill string are not clear. Its key research fields are in deep water, with ultra-deep and shallow unconventional oil and gas. The first stage of intelligent drilling, automation drilling, and expert system is to build a stable control system. Once the structure and parameters of drill string system are determined, the stability problems are identified based on the theory model, but actual drilling conditions are complex, and slender drill string, formation, and fluid formed a huge system. WOB, RPM, TOB, borehole quality, and other factors synthetically restrict each other. Every parameter has uncertain factors, which even cause opposite regularity of theory and practice results.

Downhole dynamic parameters measurement is accurate, but the development of measurement tools is difficult and expensive. Transmission signal attenuation and slow transmission speed are another key problem. In order to realize the stable control system, transmission law between bottom hole and wellhead need to be solved. The real-time 


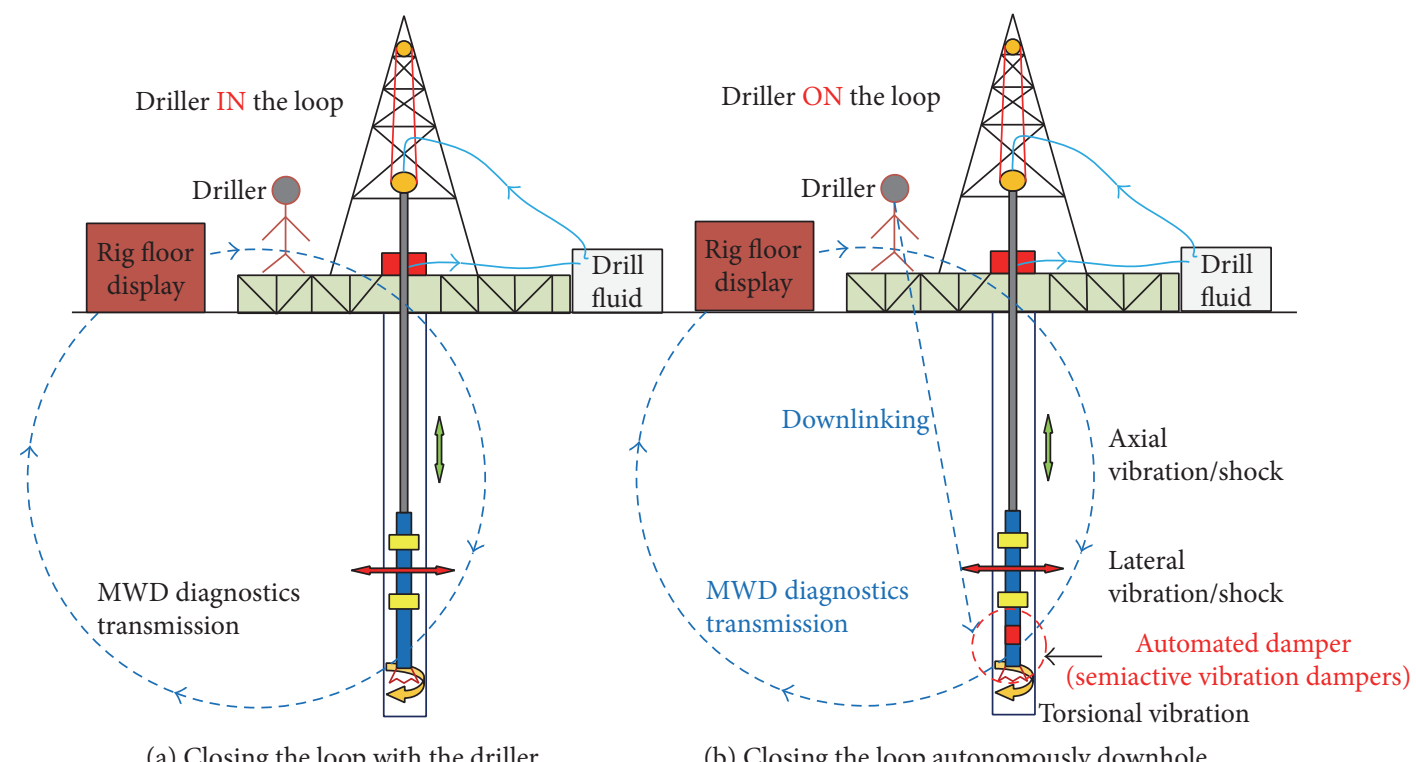

(a) Closing the loop with the driller

(b) Closing the loop autonomously downhole

FIGURE 22: Loop controlling system for the drill string V\&S.

monitoring and analysis of underground and ground date can show the real response mechanism. Classic control theories are based on transfer function [133]. So we do not need to solve complicated mathematical model to study the input signal with zero initial conditions of dynamic process. Because of the huge drilling cost and high risk in field test, an accurate physical model on the ground can simulate the downhole transmission rule. However, the physical model on the ground of transmission law of slender drill string did not come true. It is necessary to establish the physical model based on similarity criterion [134]. Aerospace and military industry has developed rapidly, so the mature control technologies in the aerospace and military industry are introduced for the control of drill string V\&S. Because the V\&S increased control difficulty and uncertainty of drilling, it not only is related to the working life of the downhole tools but also involves the borehole quality and drilling cost. It is a multiobjective dynamic optimization control problem, and the multiobjective dynamic and collaborative algorithm track control method of vehicles in the field of aerospace and military industry can be introduced for the control of drill string V\&S.

In order to take advantages of control methods and reduce the drilling cost, the hybrid control system should be established based on various control methods [135]. Passive control, active control, and semiactive control can be in a drill string system at the same time. Different control modes can be used according to the different levels of drill string vibrations and impacts.

\section{Application of the Drill String Vibrations and Shocks}

The serious V\&S of drill string should be controlled and eliminated as soon as possible; however, rational utilization of the drill string vibrations will bring huge benefits to the drilling engineering. Currently several applications of the drill string V\&S have achieved good results.

4.1. Improving ROP. ROP is one of the key technical difficulties in shale gas reservoir, which increases the drilling time and cost. Percussive-rotary drilling (PRD) plays an increasingly important role in improving the ROP as shown in Figure 24. PRD is developed from rotary drilling and percussive drilling, which take advantages of the bit V\&S. There is torsional impact drilling and axial hammer drilling. One of the earliest reports of percussion drilling technique occurred in 1940s [136]. Since then different terms have been used, such as downhole hammer, percussion hammer, Down-the-Hole hammer, percussive drill, and percussiverotary drill $[137,138]$ as shown in Figure 25. The application and performance of air hammers were evaluated by Downs et al. [139], but the application of air hammer was limited due to the manufacturing and design capabilities. The ROP with a low WOB and RPM was improved by air hammers [140-147]. Recently, impact hammer [148, 149] has been applied in drilling engineering. High-frequency torsional impact drilling (HFTID) made a good use of the torsional shock energy of drill string and bit $[150,151]$. The problem of ROP of hard and fragile formation was effectively solved by the HFTID. The use of HFTID can greatly improve the rock fragmentation efficiency, increase the tool life, and reduce cost [152]. However, because of a lack of quantitative experiments and experimental facilities for the HFTID, the rock fragmentation mechanism of HFTID cannot be completely realized, and choosing of bit and drilling parameters for HFTID is difficult. Based on the conversion of vibration energy of drill string and hydraulics energy, a vibration absorption downhole pulse generator was designed by Guan et al. [153]; the simulation model of the tool was established. 


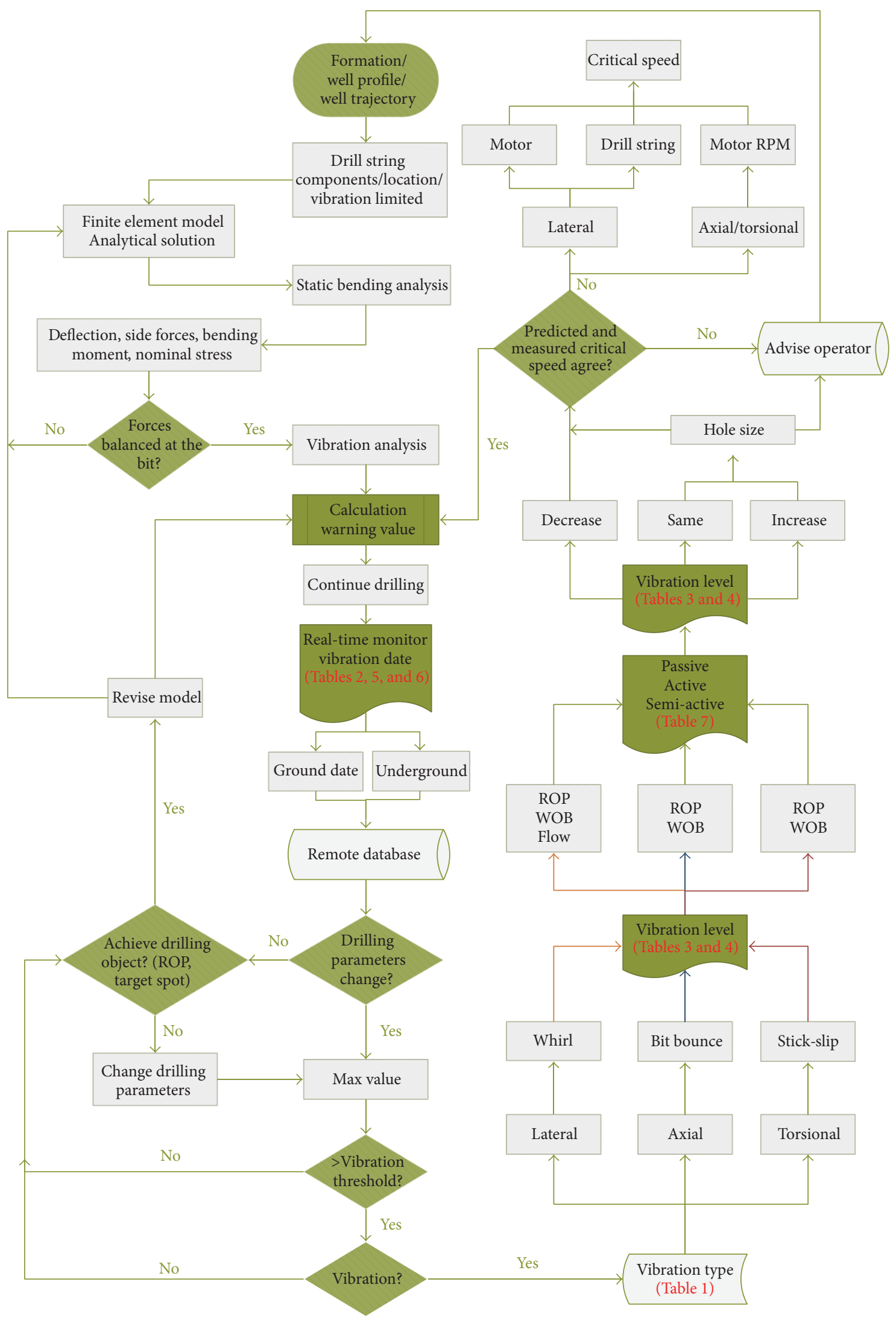

FIGURE 23: Controlling program for drill string V\&S. 


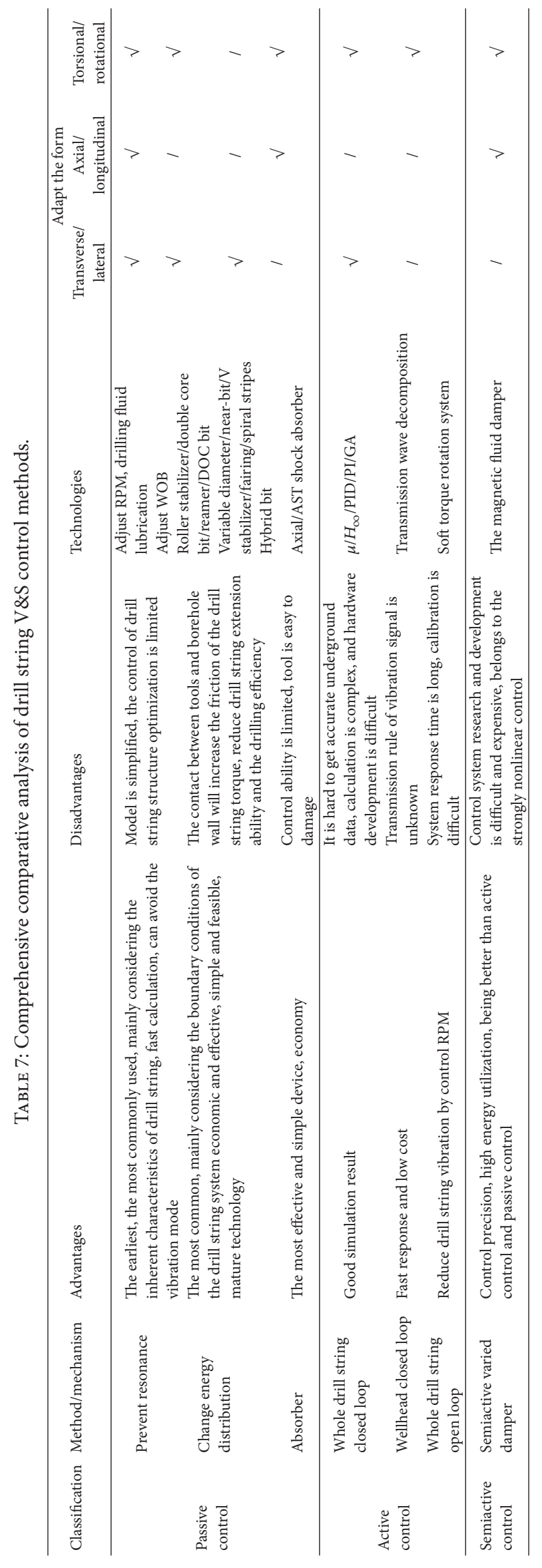




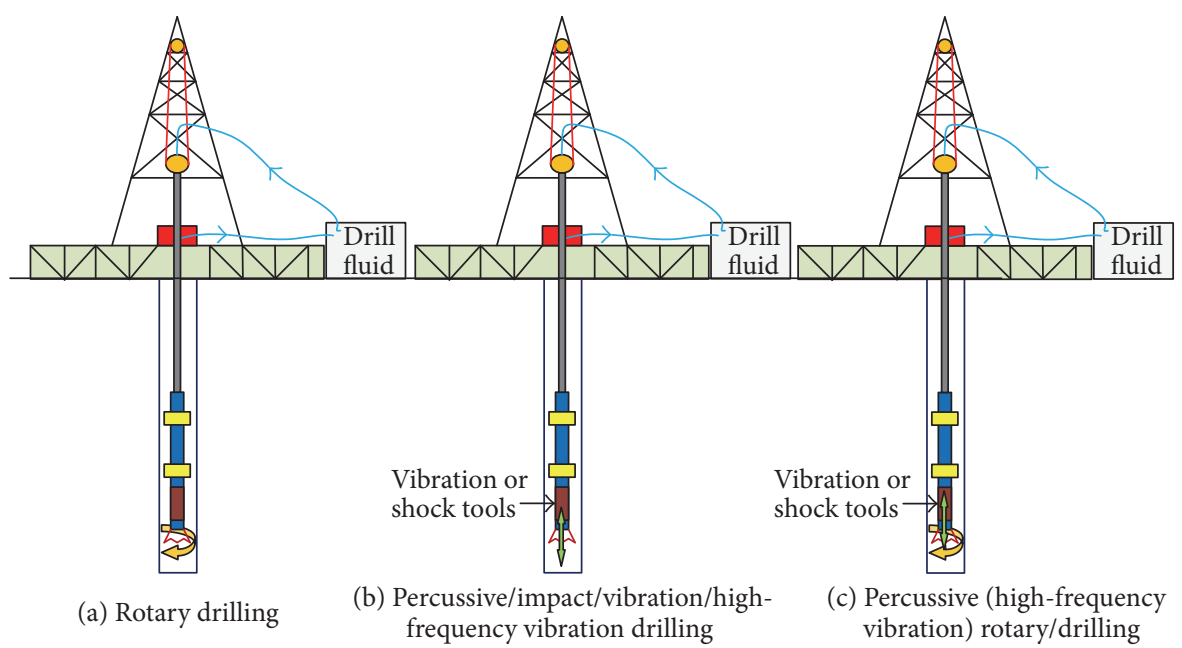

FIGURE 24: Rock fragmentation types in the dynamic drilling process.

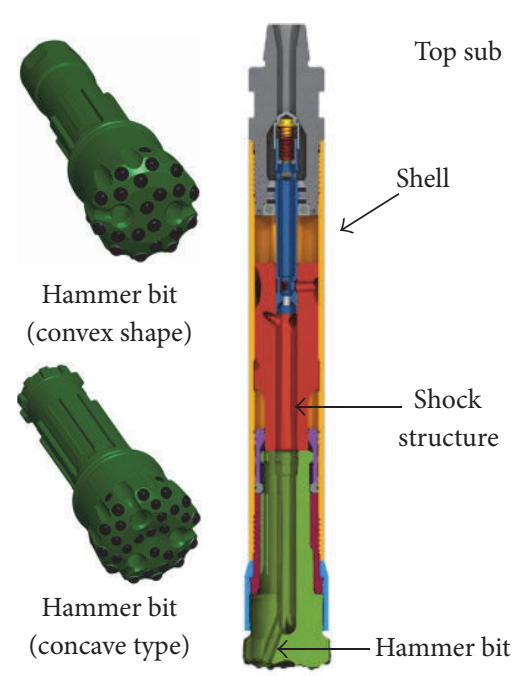

(a) Axial hammer

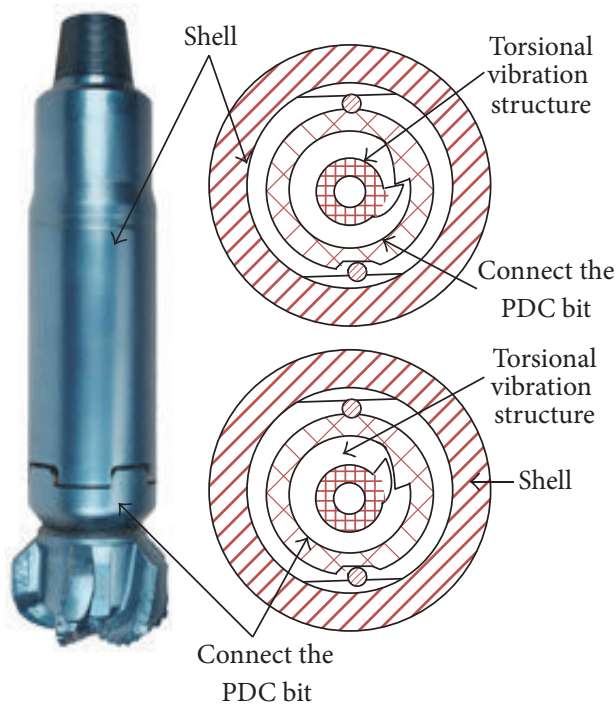

(b) Torsional hammer

FIGURE 25: The structure and working principle of typical and latest hammer.

Compared with conventional drilling tools, the device can improve the ROP, and effectively prolong the service life of drill bits. The ROP can be improved by the drilling tool with high-frequency harmonic vibration (HFHVT) [154]. The rock fragmentation mechanisms, experiments, and modeling of HFHVT have been studied by Li et al. [155], but the HFHVT is not used in the drilling field. Although PRD and HFTID have been proposed for years, they do not have a wide range of applications in oil and gas reservoirs. The ROP of $\mathrm{PRD}$ is unstable in the same formation or well. One reason is that the indentation fragmentation mechanism of rock under dynamic loads and coupled static-dynamic loads is unclear [156]. The indentation fragmentation mechanism of anisotropy shale under dynamic and static loads was studied by Dong et al. [157]. When the peak value of load is the same, energy density under dynamic-static combination load is higher than that under static load condition and rock fragmentation efficiency is also improved significantly. A quantitative evaluation method based on microindentation test technology was proposed by Chen et al. [158, 159] to research the mesomechanical properties of shale. The mesoscopic elastic modulus and indentation hardness are heterogeneous in distribution considering different influencing factor. Because of the complexity of rock heterogeneity and dynamic mechanical characteristics, the future efforts should focus on the comparative study of indentation fragmentation mechanism of shale at the multiscale and numerical simulation of dynamic damage characteristics of rock for full-sized drill bit.

4.2. Control Borehole Trajectory. The anticollision of borehole trajectory is one of the most important problems in drilling 


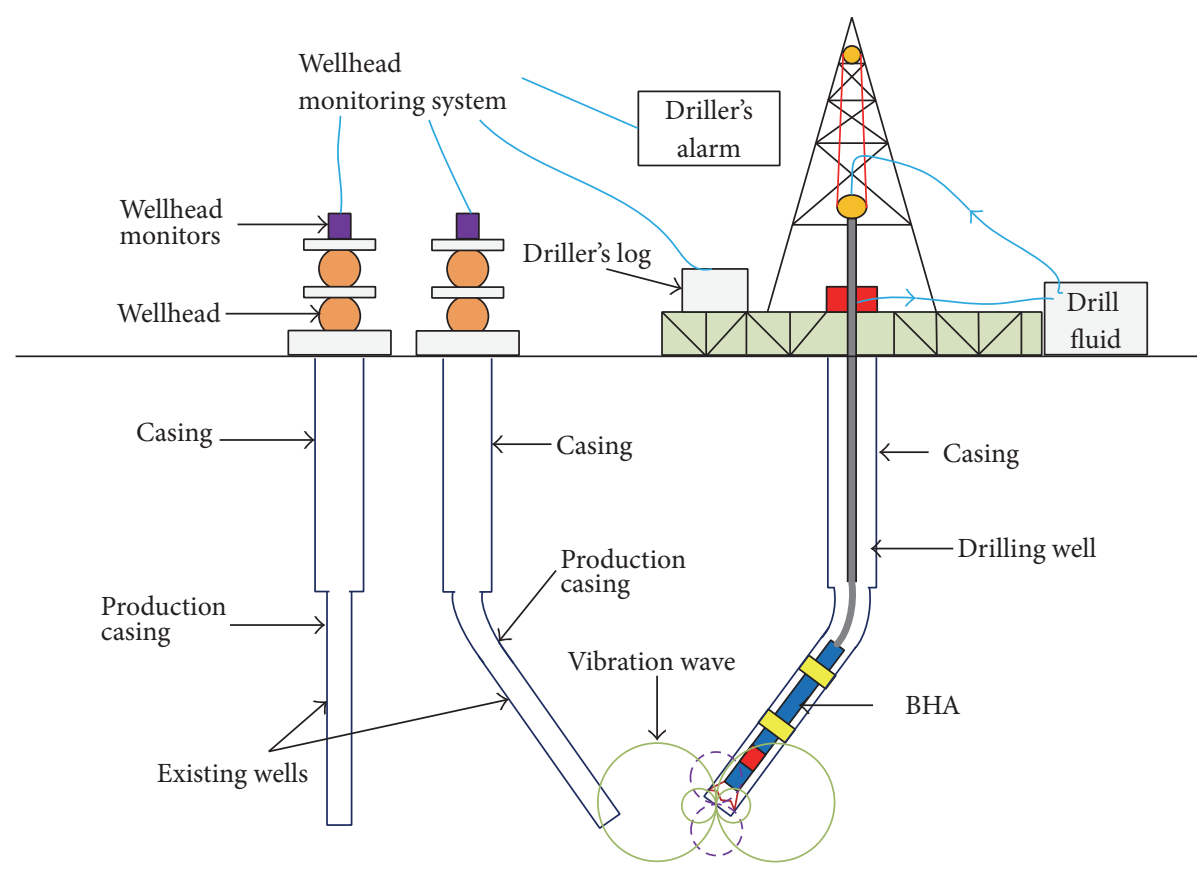

FIgURE 26: Anticollision wellhead monitoring system.

engineering. The safety warning system for reducing the collision probability of borehole trajectory was studied by Stagg and Reiley [160]. The acceleration sensor installed on the wellhead receives the downhole vibration date of rock fragmentation. The frequency range is $200 \mathrm{~Hz} \sim 400 \mathrm{~Hz}$. Based on the signal feature of drill string, the distance of the bit and casing pipe of adjacent well was estimated. When the signal characteristic value goes beyond the system threshold, the system raised the collision alarm [161], which can be used in the cluster wells as shown in Figure 26. The technology has great significance for the control of well trajectory, such as deep water well, ultra-deep water well, old oilfield drilling, and shale gas drilling.

4.3. The Source of Seismic While Drilling. Using drill bit vibration as a power source for the subsurface imaging was first proposed by Weatherby. It is remarked that the discrete impulse signals produced by the impact drilling tool can be the seismic source [162]. The technology gets fast development after the late 1980s [163]. The drill bit seismic while drilling (DB-SWD) take advantages of the drill bit vibration energy; the seismic signal was recorded by the offset array geophone and hydrophone on the surface ground or see level. The date as reference signals was measured by the pilot sensors fixed to the top of the drill string. The reference signals are used to the cross correlation processing with surface receiver records as shown in Figures 27 and 28. Due to its observation system geometric form is reciprocal to the conventional vertical seismic profiling (VSP) [16, 29]. DBSWD is also known as reverse VSP (RVSP) based on the reciprocity principle [16]. DB-SWD can obtain the overburden velocity and time-depth information used to the prediction of reflection and structures ahead of the drill bit. Using the
DB-SWD technology can overcome the drilling problems, such as sticking and loss of drill strings, and improve drilling safety and efficiency [164]; the velocity information can be used to calibrate surface seismic imaging [165]. Compared with the conventional VSP and VSP while drilling (VSP-WD) as shown in Table 8, DB-SWD does not require additional downhole explosives or air gun seismic sources. There is no interruption to the drilling operation time, and no risk to wellbore and downhole tools [30, 166-168]. The MWD seismic surveying and logging operations can be realized. However, the complexity of signal processing and downhole working conditions increase the design difficulty of downhole MWD seismic surveying and logging tools. The intensity and energy distribution of seismic source is one of the key problems of DB-SWD technology. A roller cone bit with huge WOB and TOB break rock through shear and compression failure. In contrast to roller cone drill bits, the diamond bits and poly-diamond-composite (PDC) bits broken rock through shear and grinding action; the axial loads of PDC bits are more than 10 times lower than the vertical forces of roller cone bit [169-173]. With the increase of well depth, the vibration energy attenuation of the roller cone bits increases and the geophone on the ground receives the weak source signal. Drill-rig noise enhanced the interruption to the SNR; the lower SNR of bit increase the difficulty of data processing and effective signal extraction. There are some effective solutions for the above problems. A swept impulse tool (SIT) can generate a broadband seismic signal at the DB-SWD. The SIT was proposed to overcome the limitations of DB-SWD with PDC bits in lined wells and in soft formations. The signal date volume and a large receiver array can improve the SNR $[164,174-177]$. Another approach is that the seismic signal processing is based on interferometry by deconvolution; 


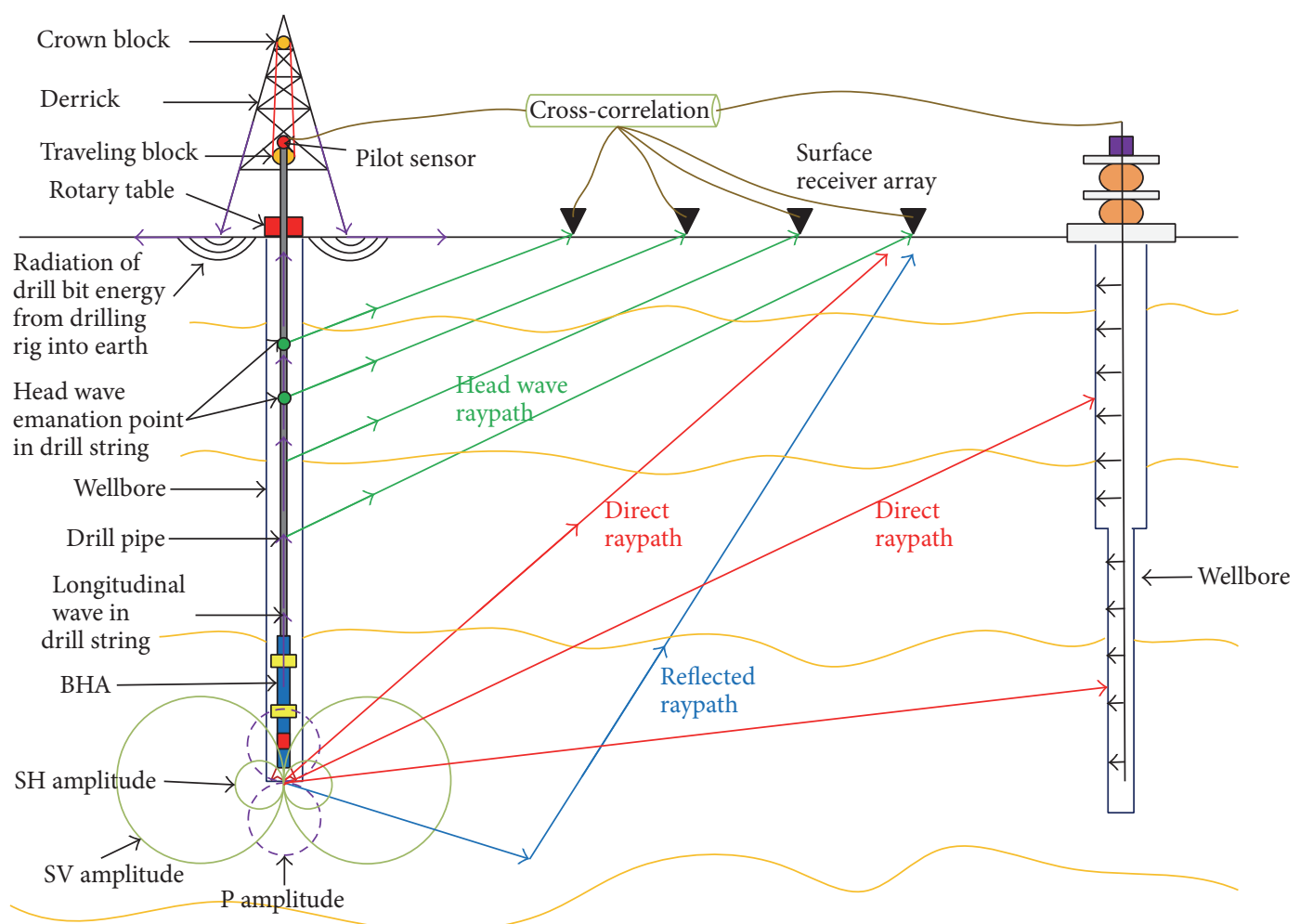

FIGURE 27: Drill bit energy radiated by the drill rig and the drill string in the vertical well.

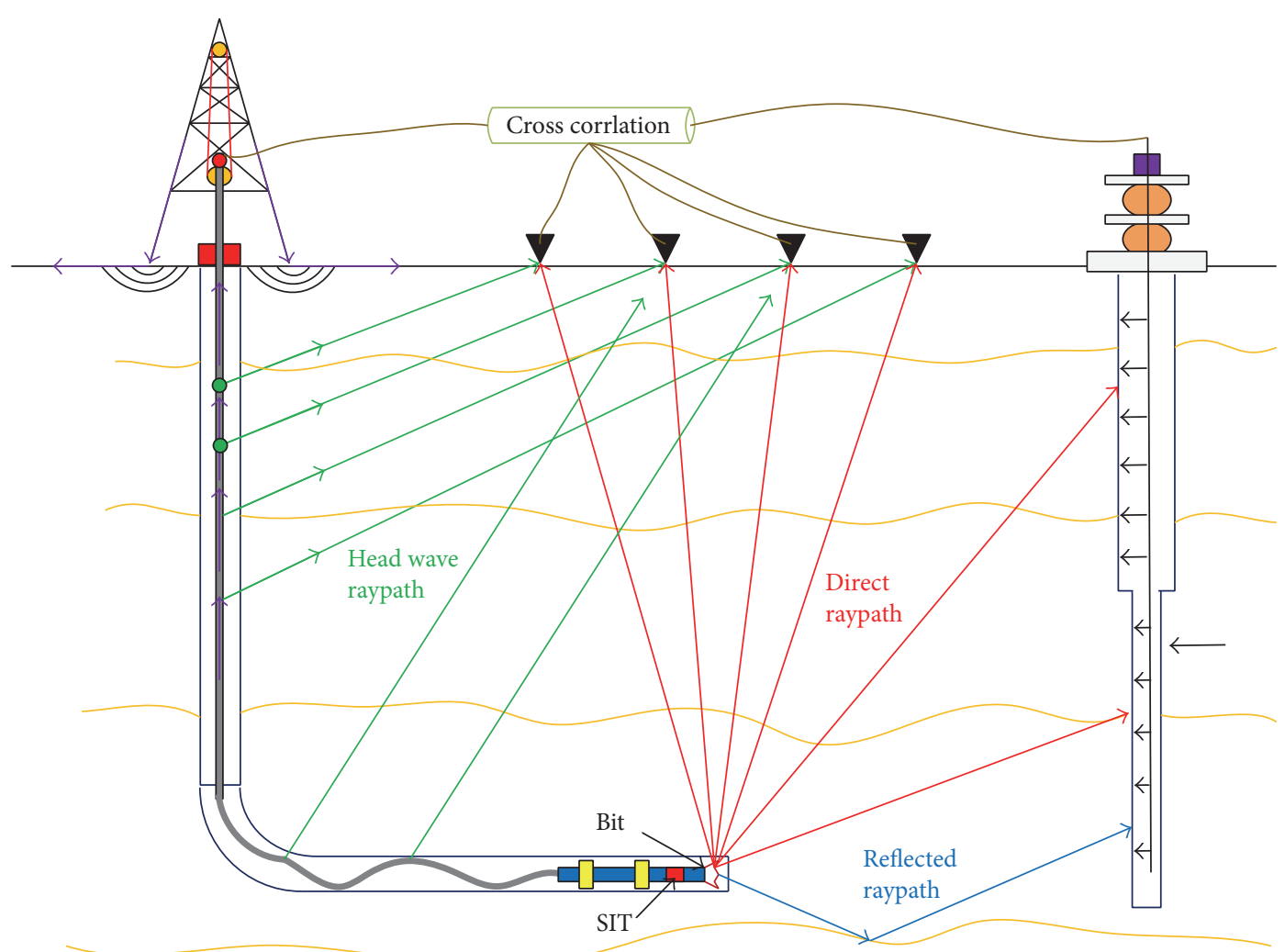

FIGURE 28: Drill bit energy radiated by the drill rig and the drill string in the directional/horizontal well. 


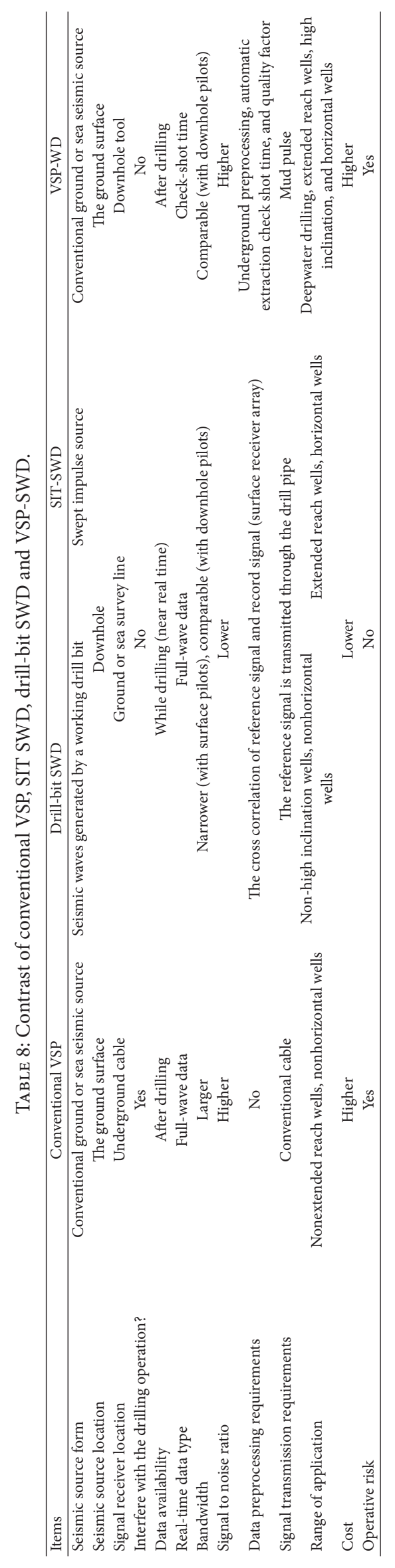




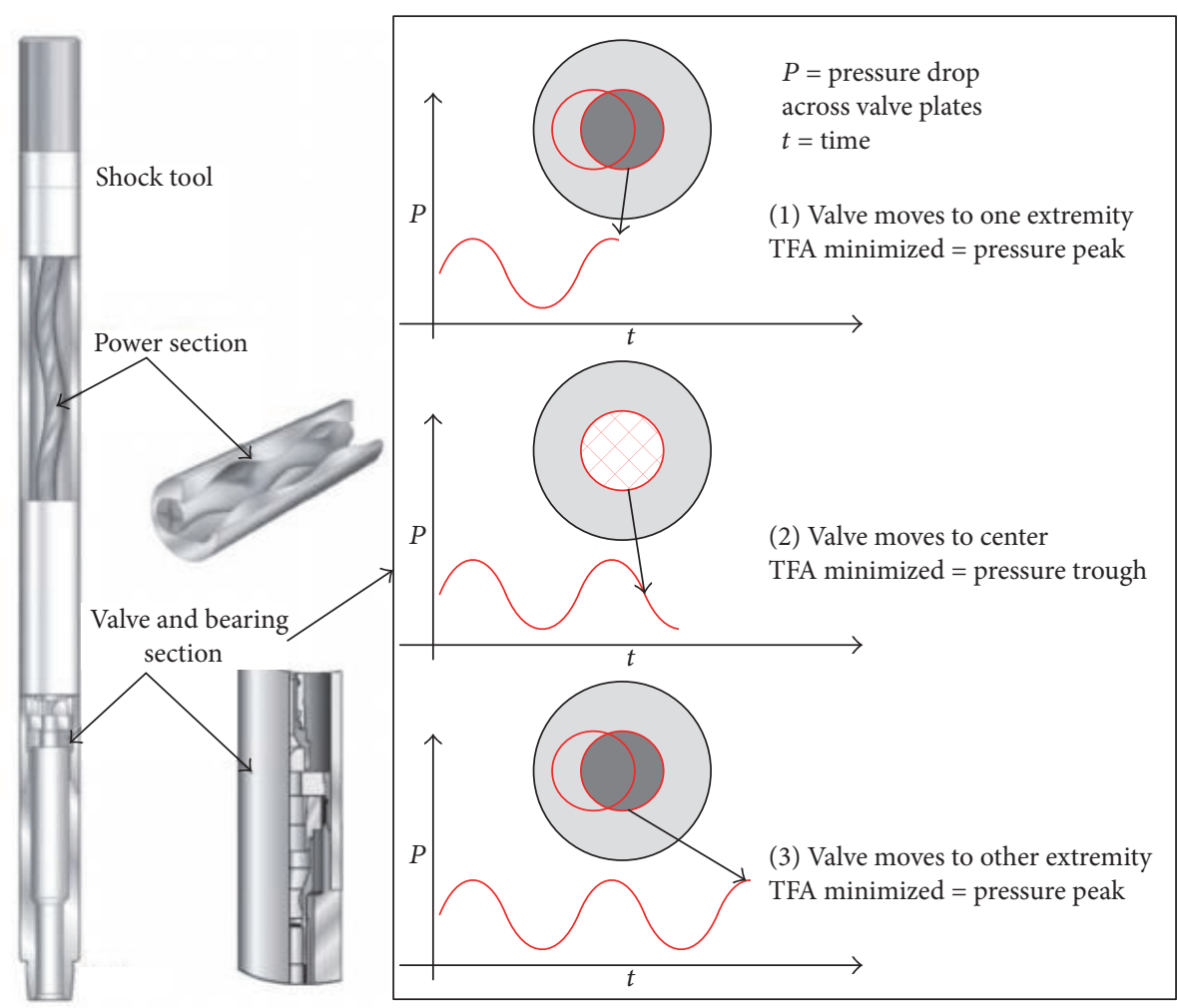

(a) AGT system

(b) Pressure pulses in AGT

FIGURE 29: AGT system and working principle.

the advantage of this method is that it does not need to know drill bits wavelet. In order to improve bit SNR, the Karhunen-Loeve (KL) transform is used to suppress drill-rig noise [178-182]. The uncontrolled characteristics of drilling stochastic vibration improve the uncertainty of downhole noise. Although an increasing number of researchers have lots of study results for the downhole signal characteristics, dynamic signal characteristics of the drill bit are unclear at present. Because of the fast development of downhole dynamic parameters measuring technologies, the acquisition and analysis of drill bit dynamic signal should be discussed in further work; the multiparameters, such as acceleration, WOB, TOB, and RPM, can be obtained quickly at the same time $[183,184]$. The control technologies of drill string vibration can be used to improve the reliability of seismic source signals [33-38, 41, 42, 44-48, 53-60, 69, 73, 95-131].

4.4. Reducing the Friction Force of Drill String. The friction force of drill string is a major problem in the coiled tubing drilling and horizontal well [185-187]. One of the effective methods to reduce the friction force is to use the drill string vibration energy. The vibration generator installed on the drill string changes the direction of friction force between drill string and borehole wall. The tool was divided into rotating sleeve and nonrotating sleeve. The rotating sleeve produces axial vibration of drill string. An axial oscillation generator tool (AGT) for coiled tubing drilling was designed by NOV as shown in Figure 29. An axial hydraulic oscillation device to reduce the friction of drill string was developed by $\mathrm{Li}$ [187], but the placement of vibrator, the optimized value of vibration frequency, and the vibration force need to be studied. Efficient utilization of drill string V\&S has become an important scientific question. The application limitation of AGT is that the mechanism of friction reduction is unclear. The coulomb friction model does not explain the change law of friction reduction caused by the AGT. A new model is proposed by Chen based on the dynamic friction model and microscopic contact deformation theory [188] as shown in Figure 30. The model can provide a quantitative calculation to predict the frictional resistance in horizontal drilling. The Dahl model is an innovation dynamic friction model, which can be used to study the friction change during slid drilling with the AGT [189-192]. Although there are some theories that provide the application of AGT, but the whole drill string friction model with AGT needs more attention in the future efforts.

\section{Conclusions}

According to past theories, indoor experiments, and field studies, related discussions and recommendations of key problems are proposed and discussed such as basic concepts, the classification and comparison of drill string V\&S forms, and the development and important indicators of vibration measuring instrument. The control method can be summarized as passive control, active control, and semiactive 


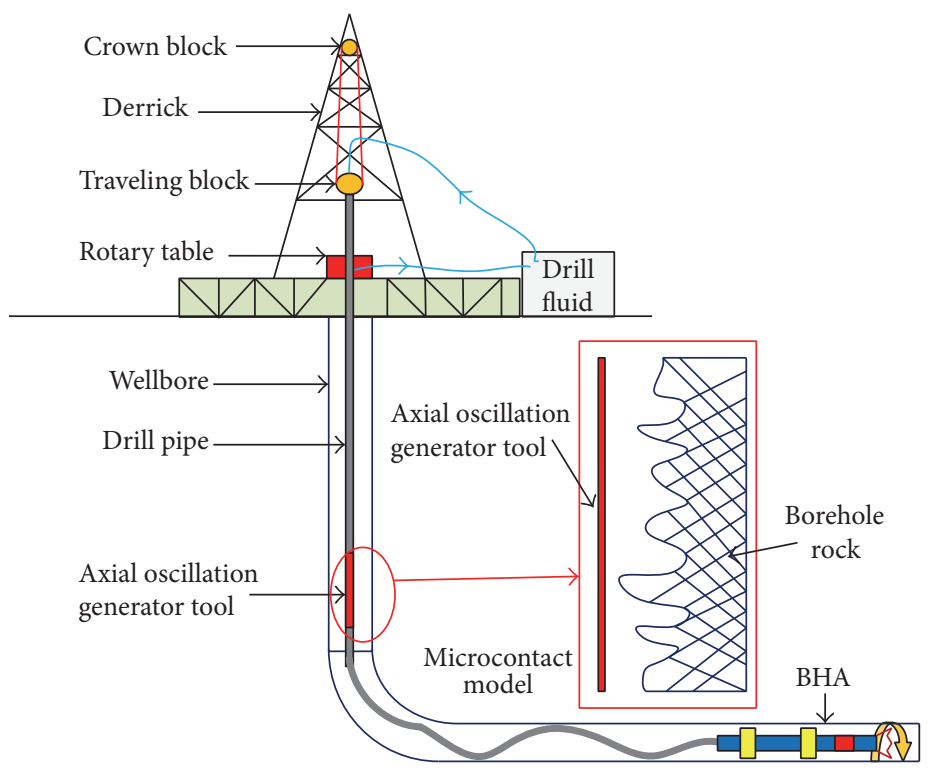

FIGURE 30: The schematic diagram of reducing the friction force of drill string.

control. Each control method is suitable for different conditions. Passive control method is given priority in addressing drill string V\&S, as active and semiactive control method are not yet mature. The control program of drill string V\&S was completed to provide a reference for "harmless" drilling. Applications technologies for the drill string V\&S include improving ROP, controlling borehole trajectory, seismic while drilling, and reducing the friction of drill string. In order to further understand the evaluation and control technologies of drill string V\&S, physical experiments should be established according to similar principles, which focus on the signal transmission rule along the drill string and the control system stability. The joint action system utilizing a variety of V\&S absorbers should be established. The hybrid control technology for drill string V\&S taking advantages of passive control, active control, and semiactive control needs to be developed.

\section{Competing Interests}

The authors declare that there is no conflict of interests regarding the publication of this paper.

\section{Acknowledgments}

This work is supported by a grant from the National Science and Technology Major Project (Grant no. 2016ZX05022001), National Science and Technology Major Project (Grant no. 2016ZX05028001), Major National Basic Research Development Program of China (973 Program) (Grant no. 2013CB228003), the Science and Technology Support Program of Sichuan Province (Grant no. 2015SZ0003), National Science and Technology Major Project (Grant no. 2015ZX05066005), the Basic Research Subject of the State Key Laboratory of Oil \& Gas Reservoir Geology and Exploitation (Southwest Petroleum University) (Grant no.
G3-1), and Open Fund of the State Key Laboratory of Oil and Gas Reservoir Geology and Exploitation of Southwest Petroleum University (Grant no. PNL201611).

\section{References}

[1] W. Hu, J. Bao, and B. Hu, "Trend and progress in global oil and gas exploration," Petroleum Exploration and Development, vol. 40, no. 4, pp. 439-443, 2013.

[2] C. Zou, Z. Yang, G. Zhang et al., "Conventional and unconventional petroleum 'orderly accumulation': concept and practical significance," Petroleum Exploration and Development, vol. 41, no. 1, pp. 14-30, 2014.

[3] G. Dong, P. Chen, T. Ma, C. Yang, and C. Ma, "Key technology of deep water top hole drilling and current situation of equipment research and application," China Petroleum Machinery, vol. 41, no. 6, pp. 49-53, 2013.

[4] X. Shi, Z. Yu, and P. Chen, Design and Control Theory of the Sidetrack Horizontal Well and Branch Wellbore Trajectory, Petroleum Industry Press, Beijing, China, 2009.

[5] P. Chen, Y. Liu, and T. Ma, "Status and prospect of multi-well pad drilling technology in shale gas," Petroleum Drilling Techniques, vol. 42, no. 3, pp. 1-7, 2014.

[6] P. Chen, Drilling and Well Completion Engineering, Petroleum Industry Press, Beijing, China, 2nd edition, 2011.

[7] M. W. Dykstra, D. C.-K. Chen, T. M. Warren, and S. A. Zannoni, "Experimental evaluations of drill bit and drill string dynamics," in Proceedings of the SPE Annual Technical Conference \& Exhibition, pp. 319-334, September 1994.

[8] J. D. Macpherson and P. Jogi, "Application and analysis of simultaneous near bit and surface dynamics measurements," in Proceedings of the IADC/SPE Drilling Conference, SPE-39397-MS, Dallas, Tex, USA, March 1998.

[9] G. Heisig, J. Sancho, and J. D. Macpherson, "Downhole diagnosis of drilling dynamics data provides new level drilling process control to driller," in Proceedings of the SPE Annual Technical 
Conference and Exhibition, Society of Petroleum Engineers, New Orleans, La, USA, September 1998.

[10] S. L. Chen, K. Blackwood, and E. Lamine, "Field investigation of the effects of stick-slip, lateral, and whirl vibrations on rollercone bit performance," SPE Drilling and Completion, vol. 17, no. 1, pp. 15-20, 2002.

[11] J. T. Finger, A. J. Mansure, S. D. Knudsen, and R. D. Jacobson, "Development of a system for diagnostic-while-drilling (DWD)," in Proceedings of the SPE/IADC Drilling Conference, Amsterdam, Netherlands, February 2003.

[12] M. E. Cobern and M. E. Wassell, "Laboratory testing of an active drilling vibration monitoring \& control system," in Proceedings of the AADE National Technical Conference \& Exhibition, pp. 57, Houston, Tex, USA, 2005.

[13] M. Reeves, J. D. MacPherson, R. Zaeper et al., "High speed drill string telemetry network enables new real time drilling and measurement technologies," in Proceedings of the IADC/SPE Drilling Conference, Society of Petroleum Engineers, Miami, Fla, USA, February 2006.

[14] L. W. Ledgerwood III, J. R. Jain, O. J. Hoffmann, and R. W. Spencer, "Downhole measurement and monitoring lead to an enhanced understanding of drilling vibrations and polycrystalline diamond compact bit damage," SPE Drilling and Completion, vol. 28, no. 3, pp. 254-262, 2013.

[15] H. Oueslati, A. Hohl, N. Makkar, T. Schwefe, and C. Herbig, "The need for high frequency vibration measurement along with dynamics modeling to understand the genesis of PDC bit damage," in Proceedings of the IADC/SPE Drilling Conference and Exhibition, Society of Petroleum, Fort Worth, Tex, USA, March 2014.

[16] J. W. Rector III and B. P. Marion, "The use of drill-bit energy as a downhole seismic source," Geophysics, vol. 56, no. 5, pp. 628634, 1991.

[17] R. F. Mitchell and M. B. Allen, "Case studies of BHA vibration failure," in Proceedings of the SPE Annual Technical Conference and Exhibition, SPE-16675-MS, Dallas, Tex, USA, September 1987.

[18] J. K. Vandlver, J. W. Nicholson, and R.-J. Shyu, "Case studies of the bending vibration and whirling motion of drill collars," SPE Drilling Engineering, vol. 5, no. 4, pp. 282-290, 1990.

[19] H. Reckmann, P. Jogi, F. T. Kpetehoto, S. Chandrasekaran, and J. D. Macpherson, "MWD failure rates due to drilling dynamics," in Proceedings of the IADC/SPE Drilling Conference and Exhibition, pp. 49-58, Society of Petroleum Engineers, New Orleans, La, USA, February 2010.

[20] R. D. Zhu, P. Chen, J. L. Zhou, and X. Li, “The development of a downhole tool used in deep water top hole drilling that can measure pressure and temperature while drilling," Machinery, vol. 1, no. 1, pp. 93-95, 2012.

[21] P. Chen and T. Ma, "Research status of early monitoring technology for deepwater drilling overflow," Acta Petrolei Sinica, vol. 35, no. 3, pp. 602-612, 2014.

[22] C. Yang, P. Chen, H. Xia, X. Han, and T. Ma, "Progress in research and development of measurement-while-drilling apparatuses," Natural Gas Industry, vol. 33, no. 2, pp. 71-75, 2013.

[23] V. A. Dunayevsky and F. Abbassian, "Application of stability approach to bit dynamics," SPE Drilling \& Completion, vol. 13, no. 2, pp. 99-107, 1998.

[24] D. W. Dareing, "Guidelines for controlling drill string vibrations," Journal of Energy Resources Technology, vol. 106, no. 2, pp. 272-277, 1984.
[25] Z.-Y. Pan, W.-C. Cui, and X.-C. Zhang, "Overview on VIV of slender marine structures," Journal of Ship Mechanics, vol. 9, no. 6, pp. 135-154, 2005.

[26] P. A. Patil and C. Teodoriu, "A comparative review of modelling and controlling torsional vibrations and experimentation using laboratory setups," Journal of Petroleum Science and Engineering, vol. 112, pp. 227-238, 2013.

[27] X. Zhu, L. Tang, and Q. Yang, "A literature review of approaches for stick-slip vibration suppression in oilwell drillstring," Advances in Mechanical Engineering, vol. 6, Article ID 967952, 2014.

[28] A. Ghasemloonia, D. Geoff Rideout, and S. D. Butt, "A review of drillstring vibration modeling and suppression methods," Journal of Petroleum Science and Engineering, vol. 131, pp. 150164, 2015.

[29] J. W. Rector III, Utilization of drill-bit vibrations as a downhole seismic source [Ph.D. thesis], Stanford University, 1990.

[30] F. B. Poletto and F. Miranda, Seismic While Drilling: Fundamentals of Drill-Bit Seismic for Exploration, Elsevier, 2004.

[31] A. S. Yigit and A. P. Christoforou, "Stick-slip and bit-bounce interaction in oil-well drillstrings," Journal of Energy Resources Technology, vol. 128, no. 4, pp. 268-274, 2006.

[32] A. Baumgart, "Stick-slip and bit-bounce of deep-hole drillstrings," Journal of Energy Resources Technology, vol. 122, no. 2, pp. 78-82, 2000.

[33] L. A. Sinor, T. M. Warren, and W. K. Armagost, "Development of an anti-whirl core bit," SPE Drilling \& Completion, vol. 10, no. 3, pp. 170-177, 1995.

[34] W. J. Yucai and G. Zhichuan, "Research on whirling mechanism of bottom drillstring and its rules by inner simulated experiments," Journal of Guangxi University: Natural Science Edition, vol. 32, no. 2, pp. 126-129, 2007.

[35] X. Zhang and Q. Di, "Strength calculation of the whirled drillstring at flexural-torsional alternate stress," Natural Gas Industry, vol. 24, no. 7, pp. 49-51, 2004.

[36] T. V. Aarrestad and A. Kyllingstad, An Experimental and Theoretical Study of Coupled Boundary Conditions for Vibrations in Drillstrings, Rogaland Research Institute, 1986.

[37] J. K. Al-Thuwaini, M. Emad, H. Hendrazid, W. Mohamed, R. Chafai, and A. D. Murdock, "Combination of unique stabilized Bi-Center bit and Vibration dampening tool improve hole opening performance through interbedded formations in Saudi Arabia," in Proceedings of the Abu Dhabi International Petroleum Exhibition and Conference, Society of Petroleum Engineers, 2008.

[38] Z. Li, Z. Wang, X. Yang, and X. Tian, "Swirling analysis of drilling strings and anti-whirl stabilizers design," Oil Drilling \& Production Technology, vol. 3, p. 36, 2008.

[39] Q. Liu and B. Huang, "Establishment of lateral vibration dynamic model of roller cone rock bit and its solution," Natural Gas Industry, vol. 21, no. 4, pp. 55-56, 2001.

[40] M. B. Allen, "BHA lateral vibrations: case studies and evaluation of important parameters," in Proceedings of the SPE/IADC Drilling Conference, Society of Petroleum Engineers, New Orleans, La, USA, March 1987.

[41] G. Heisig and M. Neubert, "Lateral drillstring vibrations in extended-reach wells," in Proceedings of the IADC/SPE Drilling Conference, Society of Petroleum Engineers, New Orleans, La, USA, Feburary 2000.

[42] Z. Wang, "Effects of the lowing drill fluid on lateral vibration and stability of the drill stem," China Petroleum Machinery, vol. 18, no. 1, pp. 31-36, 1990. 
[43] J. Z. Chi, W. Ge, and B. Guo, "Prediction of fatigue life of drillstring under axial-torsional combined vibrations," in Proceedings of the SPE Gas Technology Symposium, Society of Petroleum Engineers, Calgary, Canada, May 2006.

[44] T. V. Aarrestad, H. A. Tonnesen, and A. Kyllingstad, "Drillstring vibrations: comparison between theory and experiments on a full-scale research drilling rig," in Proceedings of the SPE/IADC Drilling Conference, Society of Petroleum Engineers, 1986.

[45] J. D. Jansen, L. van den Steen, and E. Zachariasen, "Active damping of torsional drillstring vibrations with a hydraulic top drive," SPE Drilling \& Completion, vol. 10, no. 4, pp. 250-254, 1995.z

[46] R. W. Tucker and C. Wang, "Torsional vibration control and cosserat dynamics of a drill-rig assembly," Meccanica, vol. 38, no. 1, pp. 143-159, 2003.

[47] M. Karkoub, Y. L. Abdel-Magid, and B. Balachandran, "Drillstring torsional vibration suppression using GA optimized controllers," Journal of Canadian Petroleum Technology, vol. 48, no. 12, pp. 32-38, 2009.

[48] L. Li, Nurzat, and Q. Zhang, "Adaptive PID control strategy for the drilling-rig rotary system," Acta Petrolei Sinica, vol. 32, no. 1, pp. 158-161, 2011.

[49] K. A. Macdonald and J. V. Bjune, "Failure analysis of drillstrings," Engineering Failure Analysis, vol. 14, no. 8, pp. 16411666, 2007.

[50] E. N. Sumrall and J. Shamburger, "Modular Data Acquisition for Drilling Operations," Google Patents, 2013.

[51] L. Ge, Z. Hu, and P. Chen, "Design of down-hole engineering parameters measurement while drilling system," Transducer and Microsystem Technologies, vol. 8, p. 29, 2013.

[52] T.-S. Ma and P. Chen, "Development and use of a downhole system for measuring drilling engineering parameters," Chemistry and Technology of Fuels and Oils, vol. 51, no. 3, pp. 294-307, 2015.

[53] J. D. Jansen, "Whirl and chaotic motion of stabilized drill collars," SPE Drilling Engineering, vol. 7, no. 2, pp. 107-114, 1992.

[54] R. D. Blevins, Flow-Induced Vibration, vol. 1, D. Van Nostrand Reinhold Company, New York, NY, USA, 1977.

[55] C. Feng, The measurement of vortex induced effects in flow past stationary and oscillating circular and d-section cylinders [Retrospective Theses and Dissertations, 1919-2007], University of British Columbia, 1968.

[56] H. M. Blackburn, R. N. Govardhan, and C. H. K. Williamson, "A complementary numerical and physical investigation of vortexinduced vibration," Journal of Fluids and Structures, vol. 15, no. 3-4, pp. 481-488, 2001.

[57] P. Teasdale, R. Chafai, D. P. Garcia et al., "BHA modeling coupled with high frequency downhole vibration data provides unique solution to inconsistent drilling performance in South Iraq oilfield development," in Proceedings of the IADC/SPE Asia Pacific Drilling Technology Conference and Exhibition, SPE156445-MS, Society of Petroleum Engineers, Tianjin, China, July 2012.

[58] S. Yigit and A. P. Christoforou, "Active control of stick-slip vibrations: the role of fully coupled dynamics," in Proceedings of the SPE Middle East Oil Show, SPE-68093-MS, pp. 167-181, Society of Petroleum Engineers, Manama, Bahrain, March 2001.

[59] X. Wu, L. C. Paez, U. T. Partin, and M. Agnihotri, "Decoupling stick/slip and whirl to achieve breakthrough in drilling performance," in Proceedings of the IADC/SPE Drilling Conference and Exhibition, Society of Petroleum Engineers, 2010.
[60] A. P. Christoforou and A. S. Yigit, "Fully coupled vibrations of actively controlled drillstrings," Journal of Sound and Vibration, vol. 267, no. 5, pp. 1029-1045, 2003.

[61] F. H. Deily, W. H. Dareing, G. H. Paff, J. E. Ortloff, and R. D. Lynn, "New drilling-research tool shows what happens down hole," The Oil and Gas Journal, vol. 492, no. 66, pp. 55-64, 1968.

[62] S. Wolf, M. Zacksenhouse, and A. Arian, "Field measurements of downhole drillstring vibrations," in Proceedings of the SPE Annual Technical Conference and Exhibition, Society of Petroleum Engineers, Las Vegas, Nev, USA, 1985.

[63] H. Ho, "Method and apparatus for bottom hole measurement," Google Patents, 1987.

[64] D. A. Close, S. C. Owens, and J. D. MacPherson, "Measurement of BHA vibration using MWD," in Proceedings of the SPE/IADC Drilling Conference, Society of Petroleum Engineers, Feburary 1988.

[65] P. D. Engelder, "Method and apparatus for trelemetry while drilling by changing drill string rotation angle or speed," Google Patents, 1988.

[66] X. Cheng, "Apparatuses and methods for determining temperature data of a component of an earth-boring drilling tool," Google Patents, 2015.

[67] J. Greenberg, "Weatherford sensors track vibration to increase ROP, temperature change for early kick detection," Drilling Contractor, vol. 64, no. 2, pp. 46-47, 2008.

[68] D. Denney, "Distributed-dynamics feasibility study," Journal of Petroleum Technology, vol. 65, no. 2, pp. 100-107, 2013.

[69] I. Finnie and J. J. Bailey, "An experimental study of drill-string vibration," Journal of Engineering for Industry, vol. 82, no. 2, pp. 129-135, 1960.

[70] P. R. Paslay and D. B. Bogy, "Drill string vibrations due to intermittent contact of bit teeth," Journal of Engineering for Industry, vol. 85, no. 2, pp. 187-194, 1963.

[71] K. Millheim and M. C. Apostal, "The effect of bottomhole assembly dynamics on the trajectory of a bit," Journal of Petroleum Technology, vol. 33, no. 12, pp. 322-338, 1981.

[72] D. W. Dareing, "Drill collar length is a major factor in vibration control," Journal of Petroleum Technology, vol. 36, no. 4, pp. 637644, 1984.

[73] E. Kreuzer and M. Steidl, "Controlling torsional vibrations of drill strings via decomposition of traveling waves," Archive of Applied Mechanics, vol. 82, no. 4, pp. 515-531, 2012.

[74] X. Zhu and W. Liu, "The effects of drill string impacts on wellbore stability," Journal of Petroleum Science and Engineering, vol. 109, pp. 217-229, 2013.

[75] A. Baryshnikov, A. Calderoni, A. Ligrone, and P. Ferrara, "A new approach to the analysis of drillstring fatigue behaviour," SPE Drilling \& Completion, vol. 12, no. 2, pp. 77-84, 1997.

[76] H. Li and Y. Feng, The Cases Collection of Petroleum Tubular Goods and Equipment Failure Analysis, Petroleum Industry Press, Beijing, China, 2006.

[77] E. Bailey and J. Smith, "The goodman diagram as an analytical tool to optimize fatigue life of rotary shouldered connections," in Proceedings of the SPE/IADC Drilling Conference, Society of Petroleum Engineers, Feburary 2003.

[78] M. Hossain, M. K. Rahman, S. S. Rahman, F. Akgun, and H. Kinzel, "Fatigue life evaluation: a key to avoid drillpipe failure due to die-marks," in Proceedings of the IADC/SPE Asia Pacific Drilling Technology, Society of Petroleum Engineers, Jakarta, Indonesia, September 1998. 
[79] T. H. Hill, S. E. Ellis, K. Lee, N. M. Reynolds, and N. Zheng, "An innovative design approach to reduce drill string fatigue," SPE Drilling \& Completion, vol. 20, no. 2, pp. 94-100, 2005.

[80] J. Wu, "Drill-pipe bending and fatigue in rotary drilling of horizontal wells," in Proceedings of the SPE Eastern Regional Meeting, Society of Petroleum Engineers, Columbus, Ohio, USA, October 1996.

[81] B. S. Wassell, "Method of establishing vibration limits and determining accumulative vibration damage in drilling tools," in Proceedings of the SPE Annual Technical Conference and Exhibition, Society of Petroleum Engineers, Florence, Italy, September 2010.

[82] Y. Zang, R. Wang, R. Zhang, and Z. Wang, "A failure analysis of drill string based on fault tree," Acta Petrolei Sinica, vol. 32, no. 1, pp. 171-176, 2011.

[83] Y. I. Arevalo and A. J. Fernandes, "Quantification of drillstringintegrity-failure risk using real-time vibration measurements," SPE Drilling \& Completion, vol. 27, no. 2, pp. 216-222, 2012.

[84] Y.-J. Park, A. H.-S. Ang, and Y. K. Wen, "Seismic damage analysis of reinforced concrete buildings," Journal of Structural Engineering, vol. 111, no. 4, pp. 740-757, 1985.

[85] S. L. Kramer, Geotechnical Earthquake Engineering, Pearson, New Jersey, NJ, USA, 1996.

[86] A. Arias, "A measure of earthquake intensity," in Seismic Design of Nuclear Power Plants, R. J. Hansen, Ed., Massachusetts Institute of Technology Press, Cambridge, Mass, USA, 1970.

[87] B. Maldonado, A. Arrazola, and B. Morton, "Ultradeep HP/HT completions: classification, design methodologies, and technical challenges," in Proceedings of the Offshore Technology Conference, 2006.

[88] F. Rodney, "Method and apparatus for computing drill bit vibration power spectral density," Google Patents, 2000.

[89] D. K. Ashley, X. M. McNary, and J. C. Tomlinson, "Extending BHA life with multi-axis vibration measurements," in Proceedings of the SPE/IADC Drilling Conference, pp. 89-99, Society of Petroleum Engineers, Amsterdam, The Netherlands, March 2001.

[90] R. Riddell, “On ground motion intensity indices," Earthquake Spectra, vol. 23, no. 1, pp. 147-173, 2007.

[91] G. W. Housner and P. C. Jennings, "Generation of artificial earthquakes," in Selected Earthquake Engineering Papers of George W. Housner, pp. 438-475, ASCE, 1964.

[92] E. L. Wilson, Three Dimensional Static and Dynamic Analysis of Structures: A Physical Approach with Emphasis on Earthquake Engineering, Computers and Structures Inc, 1998.

[93] F. Naeim, The Seismic Design Handbook, Springer, 1989.

[94] D. Denney, "Quantifying drillstring-integrity-failure risk: realtime vibration measurements," Journal of Petroleum Technology, vol. 64, no. 2, pp. 66-69, 2012.

[95] T. Huang and D. W. Dareing, "Buckling and lateral vibration of drill pipe," Journal of Engineering for Industry, vol. 90, no. 4, pp. 613-619, 1968.

[96] H. Menand, J. Sellami, J. Akowanou et al., "How drillstring rotation affects critical buckling load?" in Proceedings of the IADC/SPE Drilling Conference, Society of Petroleum Engineers, 2008.

[97] Z. Qu, J. Chen, and S. Liu, "Analysis of the downhole temperature affection on the inherent vibration characteristics of the drillstring containing drill fluid flow," Journal of Vibration and Shock, vol. 2, pp. 75-78, 1998.
[98] H. Oueslati, J. R. Jain, H. Reckmann, L. W. Ledgerwood III, and S. Chandrasekaran, "New insights into drilling dynamics through high-frequency vibration measurement and modeling," in Proceedings of the SPE Annual Technical Conference and Exhibition, Society of Petroleum Engineers, New Orleans, La, USA, September-October 2013.

[99] G. Akinniranye, A. Megat, H. Elsweisy, J. Palacio, B. Poedjono, and R. Goobie, "Implementation of a shock and vibration mitigation process: achieving real-time solutions and savings," SPE Drilling \& Completion, vol. 24, no. 2, pp. 301-310, 2009.

[100] Z. Li, "Fundamental equations and its applications for dynamical analysis of rod and pipe string in oil and gas wells," Acta Petrolei Sinica, vol. 20, pp. 87-90, 1999.

[101] J. R. Bailey and S. M. Remmert, "Managing drilling vibrations through BHA design optimization," SPE Drilling \& Completion, vol. 25, no. 4, pp. 458-471, 2010.

[102] M. Burgess, G. L. McDaniel, and P. K. Das, "Improving BHA tool reliability with drillstring vibration models: field experience and limitations," in Proceedings of the SPE/IADC Drilling Conference, Society of Petroleum Engineers, New Orleans, La, USA, March 1987.

[103] E. Skaugen, "The effects of quasi-random drill bit vibrations upon drillstring dynamic behavior," in Proceedings of the SPE Annual Technical Conference and Exhibition, Society of Petroleum Engineers, Dallas, Tex, USA, September 1987.

[104] P. Defourny and F. Abbassian, "Flexible bit: a new anti-vibration PDC bit concept," SPE Drilling \& Completion, vol. 13, no. 4, pp. 237-242, 1998.

[105] S. C. Johnson, "A new method of producing laterally stable PDC drill bits," SPE Drilling \& Completion, vol. 23, no. 3, pp. 314-324, 2008.

[106] S. P. Barton, H. S. May, and S. Johnson, "Gauge, cutting structure, torque control components-what really counts for optimal tool face control with FC drill bits?" SPE Drilling \& Completion, vol. 24, no. 2, pp. 293-300, 2009.

[107] R. Pessier and M. Damschen, "Hybrid bits offer distinct advantages in selected roller-cone and PDC-bit applications," SPE Drilling \& Completion, vol. 26, no. 1, pp. 96-103, 2011.

[108] G. Pelfrene, H. Sellami, and L. Gerbaud, "Mitigating stick-slip in deep drilling based on optimization of PDC bit design," in Proceedings of the SPE/IADC Drilling Conference and Exhibition, pp. 332-343, Society of Petroleum Engineers, March 2011.

[109] T. Schwefe, L. W. Ledgerwood III, J. R. Jain, D. M. Fuselier, H. Oueslati, and L. Endres, "Development and testing of stick/slipresistant PDC Bits," in Proceedings of the IADC/SPE Drilling Conference and Exhibition, Society of Petroleum Engineers, Fort Worth, Tex, USA, March 2014.

[110] T. Schwefe, L. W. Ledgerwood III, J. R. Jain, D. M. Fuselier, H. Oueslati, and L. Endres, "Development and testing of stick/slipresistant PDC bits," in Proceedings of the SPE/IADC Drilling Conference and Exhibition, pp. 974-984, March 2014.

[111] S. F. Sowers, F. E. Dupriest, J. R. Bailey, and L. Wang, "Use of roller reamers improves drilling performance in wells limited by bit and bottomhole assembly vibrations," in Proceedings of the SPE/IADC Drilling Conference and Exhibition, Society of Petroleum Engineers, 2009.

[112] S. R. Radford, M. A. Jenkins, and T. Li, "Novel concentric expandable stabilizer results in increased penetration rates and drilling efficiency with reduced vibration," in Proceedings of the SPE/IADC Drilling Conference and Exhibition, Society of Petroleum Engineers, Amsterdam, The Netherlands, March 2009. 
[113] J. P. Mccarthy, A. A. Kabbara, T. Burnett, and I. Forster, “Careful planning and application of an asymmetric vibration damping tool dramatically improves underreaming while drilling performance in deepwater drilling," in Proceedings of the SPE Deepwater Drilling and Completions Conference, Society of Petroleum Engineers, 2012.

[114] P. C. Bates, C. Bouziane, D. Nicholl et al., "Anti-vibration sub allows high signal-to-noise ratio and improved borehole quality," in Proceedings of the SPE Offshore Europe Conference and Exhibition (OE '13), pp. 34-47, Society of Petroleum Engineers, September 2013.

[115] F. Clayer, J. K. Vandiver, and H. Y. Lee, "The effect of surface and downhole boundary conditions on the vibration of drillstrings," in Proceedings of the SPE Annual Technical Conference and Exhibition, Society of Petroleum Engineers, 1990.

[116] K. S. Seines, C. Clemmensen, and N. Reimers, "Drilling difficult formations efficiently with the use of an antistall tool," SPE Drilling \& Completion, vol. 24, no. 4, pp. 531-536, 2009.

[117] N. Reimers, "Antistall tool reduces risk in drilling difficult formations," Journal of Petroleum Technology, vol. 64, no. 1, pp. 2629, 2012.

[118] A. Serrarens, M. Van de Molengraft, J. J. Kok, and L. Van den Steen, " $H{ }_{\infty}$ control for suppressing stick-slip in oil well drillstrings," IEEE Control Systems, vol. 18, no. 2, pp. 19-30, 1998.

[119] E. M. Navarro-López and R. Suárez, "Practical approach to modelling and controlling stick-slip oscillations in oilwell drillstrings," in Proceedings of the IEEE International Conference on Control Applications, pp. 1454-1460, September 2004.

[120] C. Canudas-de-Wit, M. A. Corchero, F. R. Rubio, and E. Navarro-López, "D-OSKIL: a new mechanism for suppressing stick-slip in oil well drillstrings," in Proceedings of the 44th IEEE Conference on Decision and Control and the European Control Conference (CDC-ECC '05), pp. 8260-8265, IEEE, Seville, Spain, December 2005.

[121] H. Puebla and J. Alvarez-Ramirez, "Suppression of stick-slip in drillstrings: a control approach based on modeling error compensation," Journal of Sound and Vibration, vol. 310, no. 4-5, pp. 881-901, 2008.

[122] F. A. Majeed, H. Karki, M. Karkoub, and Y. L. A. Magid, "Experimental verification of drill string vibration suppression usingan adaptive self-tuning controller," International Journal of Acoustics and Vibrations, vol. 18, no. 1, pp. 20-26, 2013.

[123] S. A. Al-Hiddabi, B. Samanta, and A. Seibi, "Non-linear control of torsional and bending vibrations of oilwell drillstrings," Journal of Sound and Vibration, vol. 265, no. 2, pp. 401-415, 2003.

[124] F. Abdulgalil and H. Siguerdidjane, "PID based on sliding mode control for rotary drilling system," in Proceedings of the International Conference on Computer as a Tool (EUROCON '05), pp.262-265, November 2005.

[125] D. Pavković, J. Deur, and A. Lisac, "A torque estimator-based control strategy for oil-well drill-string torsional vibrations active damping including an auto-tuning algorithm," Control Engineering Practice, vol. 19, no. 8, pp. 836-850, 2011.

[126] J. Deur, T. Koledić, and N. Perić, "Optimization of speed control system for electric drives with elastic coupling," in Proceedings of the IEEE International Conference on Control Applications, pp. 319-325, IEEE, Trieste, Italy, September 1998.

[127] M. M. Sarker, D. G. Rideout, and S. D. Butt, "Advantages of an lqr controller for stick-slip and bit-bounce mitigation in an oilwell drillstring," in Proceedings of the ASME International Mechanical Engineering Congress and Exposition (IMECE '12), pp. 1305-1313, American Society of Mechanical Engineers, November 2012.

[128] B. Saldivar and S. Mondié, "Drilling vibration reduction via attractive ellipsoid method," Journal of the Franklin Institute, vol. 350, no. 3, pp. 485-502, 2013.

[129] K. Javanmardi and D. T. Gaspard, "Application of soft-torque rotary table in mobile bay," in Proceedings of the SPE/IADC Drilling Conference, pp. 645-650, Society of Petroleum Engineers, New Orleans, La, USA, February 1992.

[130] M. E. Wassell, M. E. Cobern, V. Saheta, A. Purwanto, and M. Cepeda, "Active vibration damper improves performance and reduces drilling costs," World Oil, vol. 229, no. 9, pp. 109-111, 2008.

[131] M. Hutchinson, "Automated downhole vibration damping," in Proceedings of the SPE/IADC Middle East Drilling Technology Conference \& Exhibition, Society of Petroleum Engineers, Dubai, UAE, October 2013.

[132] M. Hutchinson, D. Burgess, F. Thompson, and A. Kopfstein, Self-Adapting Bottom Hole Assembly Vibration Suppression, Society of Petroleum Engineers, 2013.

[133] S. Hu, The Principle of Automatic Control, Science Press, Beijing, China, 5th edition, 2007.

[134] G. Lin, T. Zhu, and B. Lin, "Similarity technique for dynamic structural model test," Journal of Dalian University of Technology, vol. 40, pp. 1-8, 2000.

[135] X. P. Do and S.-B. Choi, "High loaded mounts for vibration control using magnetorheological fluids: review of design configuration," Shock and Vibration, vol. 2015, Article ID 915859, 18 pages, 2015.

[136] E. Harpst and E. E. Davis, "Rotary percussion drilling," Oil and Gas Journal, vol. 11, no. 1, pp. 10-15, 1949.

[137] A. Pratt, "Modifications to and experience with percussion air drilling," in Proceedings of the SPE/IADC Drilling Conference, pp. 15-18, New Orleans, La, USA, March 1987.

[138] Y. Melamed, A. Kiselev, M. Gelfgat, D. Dreesen, and J. Blacic, "Hydraulic hammer drilling technology: developments and capabilities," Journal of Energy Resources Technology, vol. 122, no. 1, pp. 1-7, 2000.

[139] H. F. Downs, Application and Evaluation of Air-Hammer Drilling in the Permian Basin. Drilling and Production Practice, American Petroleum Institute, Washington, DC, USA, 1960.

[140] C. A. Pratt, "Modifications to and experience with air-percussion drilling," SPE Drilling Engineering, vol. 4, no. 4, pp. 315320, 1989.

[141] M. C. Whiteley and W. P. England, "Air drilling operations improved by percussion bit/hammer tool tandem," in Proceedings of the SPE/IADC Drilling Conference, Society of Petroleum Engineers, 1985.

[142] R. P. Johns, C. Witt, and M. Frederick, "Hammer bits control deviation in crooked hole country," in Proceedings of the SPE/IADC Drilling Conference, pp. 341-18659, Society of Petroleum Engineers, New Orleans, La, USA, March 1989.

[143] C. H. Reinsvold, J. Clement, M. Oliver, C. Witt, and J. Crockett, "Diamond-enhanced hammer bits reduce cost per foot in the Arkoma and Appalachian basins," in Proceedings of the SPE/IADC Drilling Conference, Society of Petroleum Engineers, Febeuary-March 1988.

[144] J. Meyers and M. Sagan, "Air hammers cut Barnett Shale drilling time in half," World Oil, vol. 225, no. 9, pp. 71-72, 2004.

[145] P. Vieira, C. Lagrandeur, and K. Sheets, "Hammer drilling technology - the proved solution to drill hard rock formations 
in the Middle East," in Proceedings of the SPE Middle East Oil and Gas Show and Conference, Society of Petroleum Engineers, Manama, Bahrain, September 2011.

[146] R. Wedel, S. Mathison, G. Hightower, and C. Staley, "Mitigating bit related stick slip with a torsional impact hammer," in Proceedings of the AADE National Technical Conference and Exhibition, 2011.

[147] H. Gao, J. Qu, and P. Zeng, "Research and practice to improve drilling speed in Yuanba Area," Petroleum Drilling Techniques, vol. 38, no. 4, pp. 26-29, 2010.

[148] Q. Sun, Y. Zhang, S. Li, and X. Wang, "Application of bit torsional impact generator in well Yuanba 10," Petroleum Drilling Techniques, vol. 38, no. 6, pp. 84-87, 2010.

[149] X.-H. Zhu, L.-P. Tang, and H. Tong, "Rock breaking mechanism of a high frequency torsional impact drilling," Journal of Vibration and Shock, vol. 31, no. 20, pp. 75-109, 2012.

[150] C. A. Deen, R. J. Wedel, A. Nayan, S. K. Mathison, and G. Hightower, "Application of a torsional impact hammer to improve drilling efficiency," in Proceedings of the SPE Annual Technical Conference and Exhibition (ATCE '11), pp. 3740-3750, Denver, Colo, USA, November 2011.

[151] P. Ge, Q. Ma, and M. Guo, "Application of air hammer drilling technology in continental well in Yuanba Block," China Petroleum Machinery, vol. 8, 2013.

[152] Y. Kong and J. Zhang, "Air hammer used in puguang gas field," Chinese Journal of Engineering Geophysics, vol. 5, no. 2, pp. 237241, 2008.

[153] Z. Guan, H. Zhang, W. Zhang, Y. Liu, and D. Liang, "Equipment and technique for improving penetration rate by the transformation of drill string vibration to hydraulic pulsating jet," Petroleum Exploration and Development, vol. 41, no. 5, pp. 678683, 2014.

[154] W. Li, T. Yan, S. Li, and X. Zhang, "Rock fragmentation mechanisms and an experimental study of drilling tools during highfrequency harmonic vibration," Petroleum Science, vol. 10, no. 2, pp. 205-211, 2013.

[155] S. Q. Li, T. Yan, W. Li, and F. Q. Bi, "Modeling of vibration response of rock by harmonic impact," Journal of Natural Gas Science and Engineering, vol. 23, pp. 90-96, 2015.

[156] M. Haftani, B. Bohloli, A. Nouri, M. R. M. Javan, M. Moosavi, and M. Moradi, "Influence of penetration rate and indenter diameter in strength measurement by indentation testing on small rock specimens," Rock Mechanics and Rock Engineering, vol. 48, no. 2, pp. 527-534, 2015.

[157] G. J. Dong, P. Chen, and T. S. Ma, "Indentation fragmentation mechanism of anisotropy shale under dynamic and static loads," in Rock Dynamics: From Research to Engineering: Proceedings of the 2nd International Conference on Rock Dynamics and Applications, J. Zhao, Ed., chapter 38, pp. 283-288, CRC Press, 2016.

[158] Q. Han, P. Chen, and T. Ma, "Influencing factor analysis of shale micro-indentation measurement," Journal of Natural Gas Science and Engineering, vol. 27, pp. 641-650, 2015.

[159] P. Chen, Q. Han, T. Ma, and D. Lin, “The mechanical properties of shale based on micro-indentation test," Petroleum Exploration and Development, vol. 42, no. 5, pp. 723-732, 2015.

[160] T. O. Stagg and R. H. Reiley, "Watchdog: an anti-collision wellhead monitoring system," in Proceedings of the International Arctic Technology Conference, Society of Petroleum Engineers, Anchorage, Alaska, USA, May 1991.
[161] G. Liu, Q. Yang, Z. Dong, B. He, and Z. Geng, "A drill bit vibration anti-collision monitoring system and field experiment," Natural Gas Industry, vol. 33, no. 6, pp. 66-70, 2013.

[162] Google Patents, "Method of making sub-surface determinations," 1936.

[163] B. A. Hardage, "Vertical seismic profiling, part A: principles," in Handbook of Geophysical Exploration, K. Helbig and S. Treitel, Eds., Geophysical Press, London, UK, 1983.

[164] B. Sun, A. Bóna, B. Zhou, A. King, C. Dupuis, and A. Kepic, "Drill-rig noise suppression using the Karhunen-Loéve transform for seismic-while-drilling experiment at Brukunga, South Australia," Exploration Geophysics, vol. 47, no. 1, pp. 44-57, 2015.

[165] J. W. Rector III and B. A. Hardage, "Radiation pattern and seismic waves generated by a working roller-cone drill bit," Geophysics, vol. 57, no. 10, pp. 1319-1333, 1992.

[166] C. Naville, S. Serbutoviez, A. Throo, O. Vincké, and F. Cecconi, "Seismic While Drilling (SWD) techniques with downhole measurements, introduced by IFP and its partners in 19902000," Oil \& Gas Science and Technology, vol. 59, no. 4, pp. 371403, 2004.

[167] A. Anchliya, "A review of seismic while drilling (SWD) techniques: a journey from 1986 to 2005," in Proceedings of the SPE Europec/EAGE Annual Conference and Exhibition, Society of Petroleum Engineers, 2006.

[168] B. Hardage, "Seismic-while-drilling: techniques using the drill bit as the seismic source," AAPG Explorer, 2009.

[169] F. Poletto, "Energy balance of a drill-bit seismic source, part 2: drill-bit versus conventional seismic sources," Geophysics, vol. 70, no. 2, pp. T29-T44, 2005.

[170] R. L. Kirlin and W. J. Done, Covariance Analysis for Seismic Signal Processing, SEG Books, 1999.

[171] H. C. Vennin, "Drilling bits optimized for the Paris basin," Oil and Gas Journal, vol. 87, no. 31, 1989.

[172] F. Poletto, F. Miranda, P. Corubolo, and F. Abramo, "Seismic while drilling using PDC signals-Seisbit ${ }^{\circledR}$ experience and perspectives," in Proceedings of the in 59th EAGE Conference of Exhibition, Geneva, Switzerland, May 1997.

[173] M. Malusa, F. Poletto, and F. Miranda, "SWD using lateral vibrations of PDC bits," in Proceedings of the SEG Annual Meeting, Society of Exploration Geophysicists, Dallas, Tex, USA, October 2003.

[174] J. J. Kolle and K. Theimer, "Seismic-while-drilling using a swept impulse source," in Proceedings of the SPE/IADC Drilling Conference, Society of Petroleum Engineers, Amsterdam, The Netherlands, February 2005.

[175] M. Malusa, F. Poletto, and F. Miranda, "Prediction ahead of the bit by using drill-bit pilot signals and reverse vertical seismic profiling (RVSP)," Geophysics, vol. 67, no. 4, pp. 1169-1176, 2002.

[176] J. B. U. Haldorsen, D. E. Miller, and J. J. Walsh, "Walk-away VSP using drill noise as a source," Geophysics, vol. 60, no. 4, pp. 978997, 1995.

[177] I. Vasconcelos and R. Snieder, "Interferometry by deconvolution: part 2-theory for elastic waves and application to drill-bit seismic imaging," Geophysics, vol. 73, no. 3, pp. S129-S141, 2008.

[178] I. Vasconcelos and R. Snieder, "Interferometry by deconvolution, Part 1-theory for acoustic waves and numerical examples," Geophysics, vol. 73, no. 3, pp. S115-S128, 2008.

[179] K. M. Al-Yahya, "Application of the partial Karhunen-Loève transform to suppress random noise in seismic sections," Geophysical Prospecting, vol. 39, no. 1, pp. 77-93, 1991. 
[180] R. Montagne and G. L. Vasconcelos, “Optimized suppression of coherent noise from seismic data using the Karhunen-Loève transform," Physical Review E, vol. 74, no. 1, Article ID 16213, 2006.

[181] K. Wapenaar and J. Fokkema, "Green's function representations for seismic interferometry," Geophysics, vol. 71, no. 4, pp. SI33SI46, 2006.

[182] J. Garnier and G. Papanicolaou, "Passive sensor imaging using cross correlations of noisy signals in a scattering medium," SIAM Journal on Imaging Sciences, vol. 2, no. 2, pp. 396-437, 2009.

[183] F. Poletto, M. Malusa, F. Miranda, and U. Tinivella, "Seismicwhile-drilling by using dual sensors in drill strings," Geophysics, vol. 69, no. 5, pp. 1261-1271, 2004.

[184] B. Cornish and R. Deady, "Multi-sensor seismic-while-drilling," in Proceedings of the SPWLA 47th Annual Logging Symposium, Society of Petrophysicists and Well-Log Analysts, Veracruz, Mexico, June 2006.

[185] A. Alali and S. P. Barton, "Unique axial oscillation tool enhances performance of directional tools in extended reach applications," in Proceedings of the Brasil Offshore, Society of Petroleum Engineers, Macaé, Brazil, June 2011.

[186] R. Gee, I. Forster, J. R. Clausen, J. Prill, and A. E. Schen, "Drilling with induced vibrations improves ROP and mitigates stick/slip in vertical and directional wells," in Proceedings of the IADC/ SPE Drilling Conference and Exhibition, Society of Petroleum Engineers, 2014.

[187] B. Li, "Development and pilot test of hydro-oscillator," Petroleum Drilling Techniques, vol. 42, no. 1, pp. 111-113, 2014.

[188] Y. Liu, P. Chen, X. Wang, and T. Ma, "Modeling frictionreducing performance of an axial oscillation tool using dynamic friction model," Journal of Natural Gas Science and Engineering, vol. 33, pp. 397-404, 2016.

[189] P. R. Dahl, "Solid friction damping of mechanical vibrations," AIAA Journal, vol. 14, no. 12, pp. 1675-1682, 1976.

[190] P. A. Bliman, "Mathematical study of the Dahl's friction model," European Journal of Mechanics A: Solids, vol. 11, no. 6, pp. 835$848,1992$.

[191] L. Skyles, Y. Amiraslani, and J. Wilhoit, "Converting static friction to kinetic friction to drill further and faster in directional holes," in Proceedings of the IADC/SPE Drilling Conference and Exhibition, Society of Petroleum Engineers, San Diego, Calif, USA, March 2012.

[192] R. Gee, C. Hanley, R. Hussain, L. Canuel, and J. Martinez, "Axial oscillation tools vs. lateral vibration tools for friction reduction-what's the best way to shake the pipe?" in Proceedings of the SPE/IADC Drilling Conference and Exhibition, Society of Petroleum Engineers, London, UK, March 2015. 


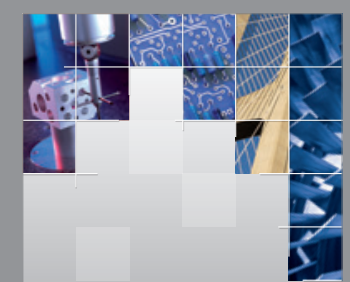

\section{Enfincering}
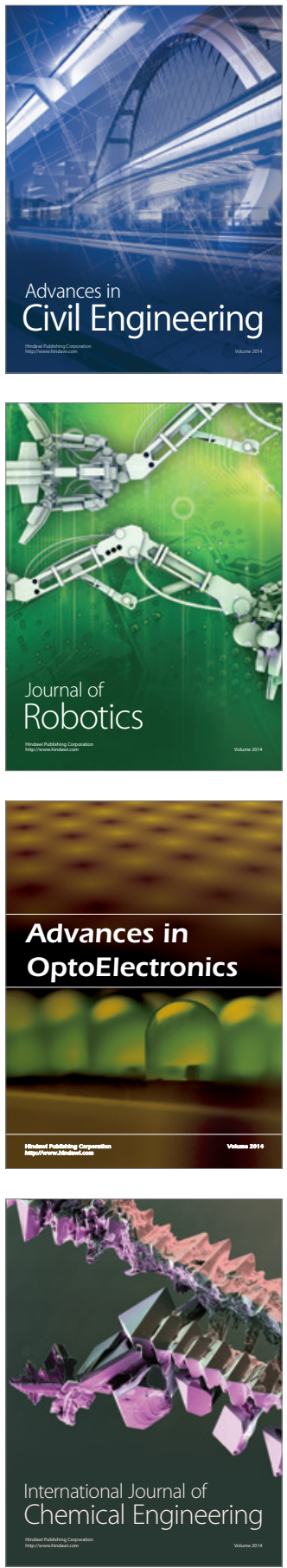

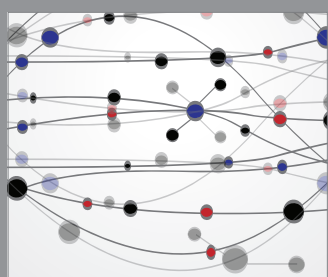

The Scientific World Journal

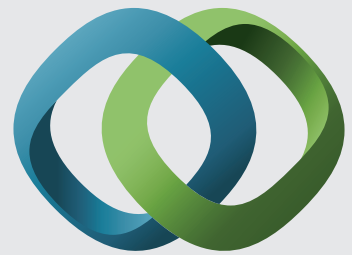

\section{Hindawi}

Submit your manuscripts at

http://www.hindawi.com
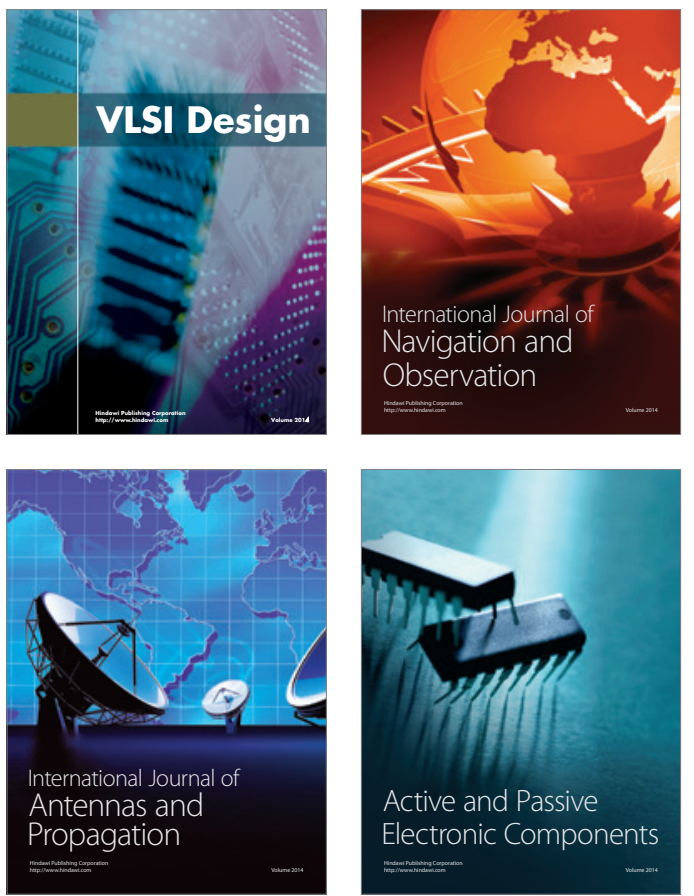
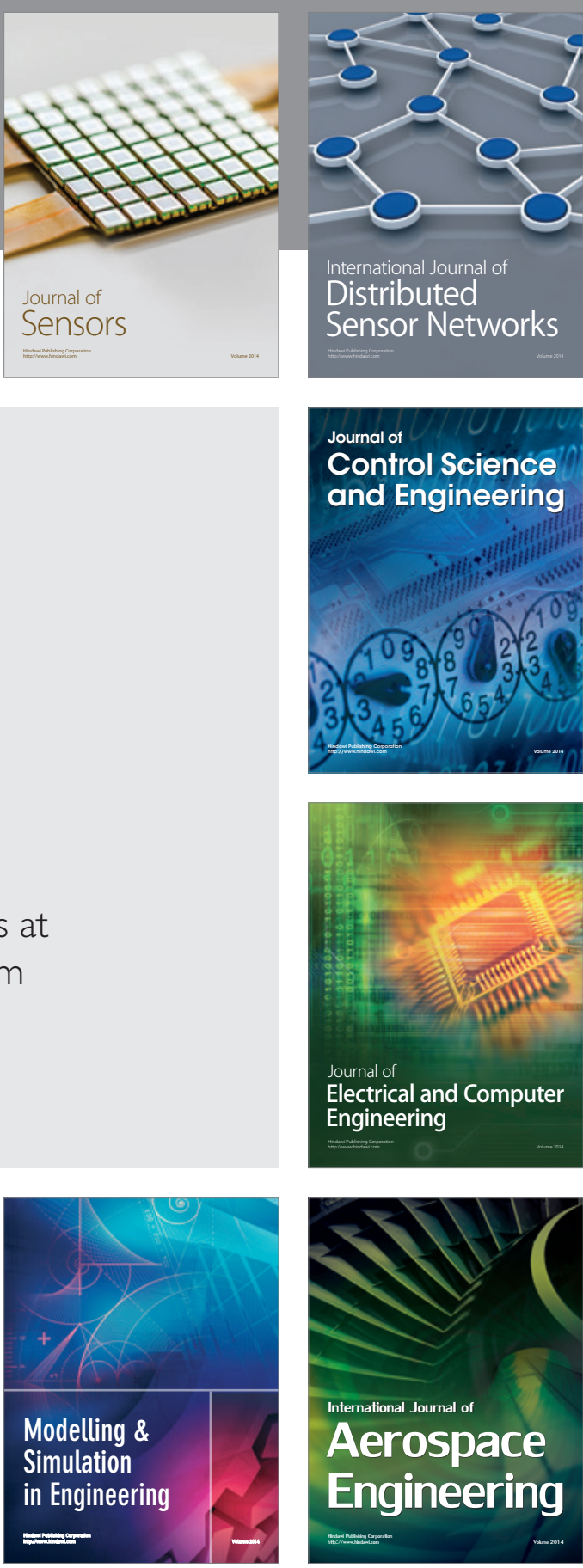

International Journal of

Distributed

Sensor Networks

Journal of

Control Science

and Engineering
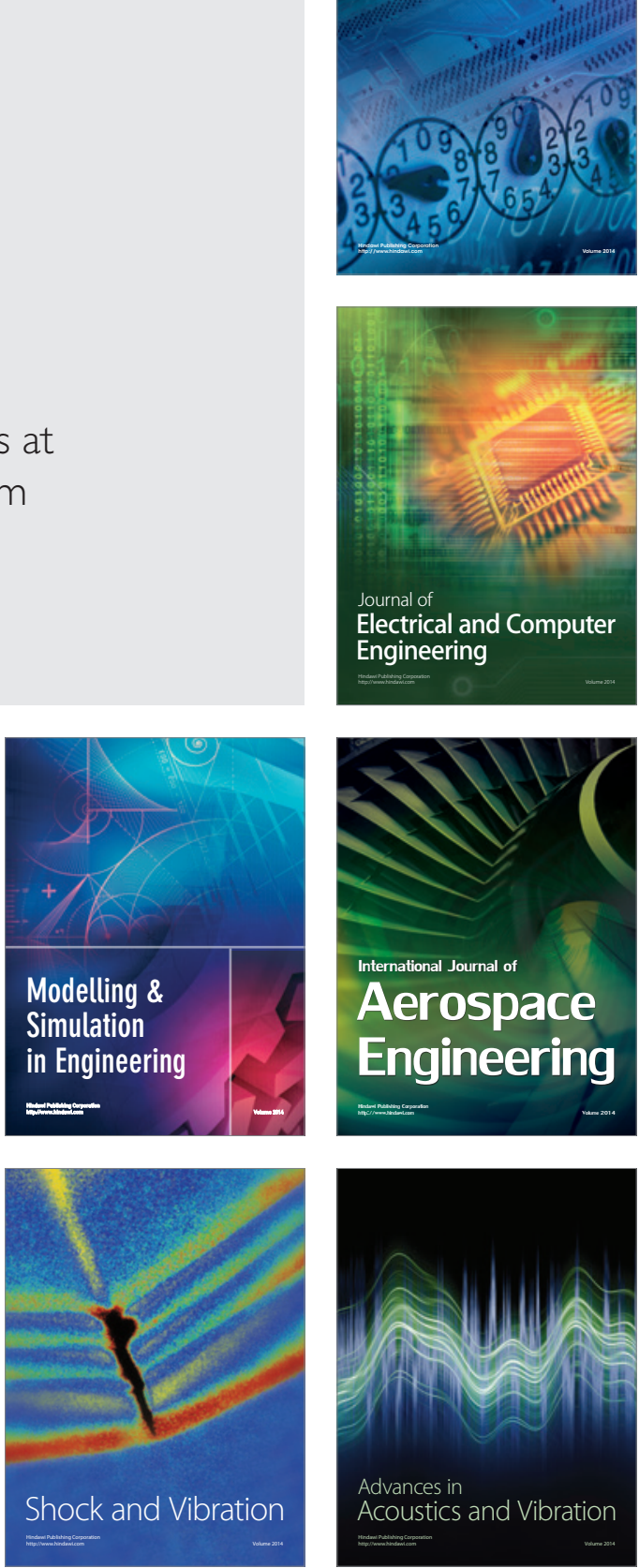